\title{
A Solid State Approach to Synthesis Advanced Nanomaterials for Thermal Spray Applications
}

\author{
Behrooz Movahedi \\ Department of Nanotechnology Engineering, \\ Faculty of Advanced Sciences and Technologies, University of Isfahan,
}

Iran

\section{Introduction}

Preparation of feedstock powders is the first step for synthesis of thermal spray coatings. A number of techniques that are capable of producing these materials include gas/water atomization, mechanical alloying/milling, thermo-chemical method, spray drying, agglomeration and sintering, plasma fusion, and sol-gel processing techniques (Berndt, 1992). Solid state synthesis is attributed to the chemical reaction and alloying performed at temperature which reactants are solid. As a result, the kinetics of solid state reactions are limited by the rate at which reactant species are able to diffuse across phase boundaries and through intervening product layers. Hence, the conventional solid state technique invariably require the use of high processing temperatures to ensure that diffusion rate is maintained at a high level (Schmalzried, 1995; Stein et al., 1993). More recently, the mechanical milling process has attracted considerable interest, primarily as a result of its potential to generate nanocrystalline and other non-equilibrium structures in large quantities at low temperature. This process is considered as a means to mechanically induced solid state reaction that occur in feedstock powder mixture during collision in the grinding media (Suryanarayana, 2001).

The aim of this chapter is to describe the fundamental, mechanisms and recent developments of solid state approach to synthesis thermal spray advanced materials and related coatings.

\section{Solid state synthesis of thermal spray powders}

Mechanical milling as a solid state synthesis usually performed using ball milling equipments that generally divided to "low energy" and "high energy" category based on the value of induced the mechanical energy to the powder mixture. The ball milling equipments used for mechanical grinding or mixing are low energy such as Horizontal mill (Tumbler). The speed of the low energy rod or ball mill is quite critical with regards to the efficiency of the process (Fig. 1). It is necessary for the balls (or rods) to drop from the top of the mill onto the feedstock material that is being ground (Fig. 1b). If the mill speed is too fast then the media will not fall at all due to centrifugal forces or it will fall directly onto the media near the bottom of the mill (Fig. 1c). At low speeds the media does not drop at all, whereas at the optimum speed the media continuously "cascades" onto the feedstock material that is being crushed (Brendt, 1992). 


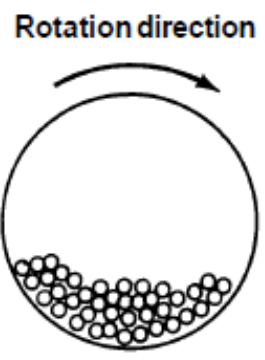

(a)

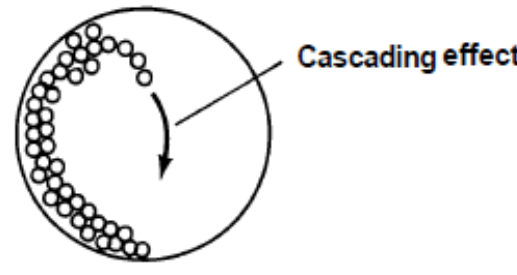

(b)

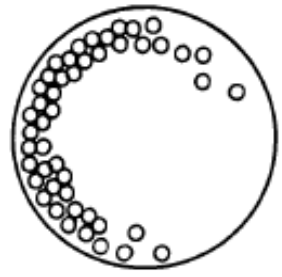

(c)

Fig. 1. Low energy mechanical milling variable that control particle grinding and efficiency: (a) low speed, (b) optimum speed, and (c) high speed (Berndt, 1992).

In mechanical milling processes that utilize to change the chemical composition of precursors, the high energy ball milling equipments is generally used. This phenomenon can be performed in various types of high energy ball mills, including attrition, planetary, and vibratory mills that schematically shown in Fig. 2. In an attrition mill, the rotating impeller cause to relative movement between balls and powders. In a planetary ball mill, a rotating disc and vials revolve in opposite direction in order of several hundred rpm. In a vibratory mill that also known as a shaker mill, the vessel is set in $1 \mathrm{D}$ or $3 \mathrm{D}$ vertical oscillatory motion. Spex 8000 is a commercial type of 3D vibratory mills. (Suryanarayana, 2001, 2004). Of the above types of mills, only the attritor mill has the highest capacity of powder charge. Accordingly, the attritor milling is employed to synthesize thermal spray feedstock powders used for the fabrication of nanostructured coatings.
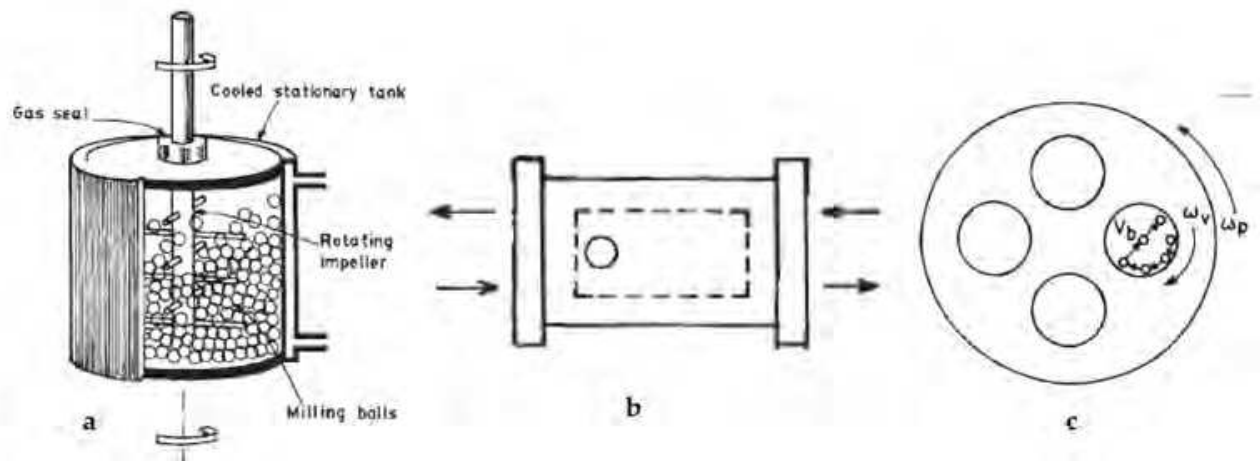

Fig. 2. Various types of high energy ball mills: (a) attrition mill, (b) vibratory mill, and (c) planetary mill (Suryanarayana, 2004).

High-energy mechanical milling is a low-cost process for the production of nanostructured powders and applicable to a variety of advanced materials (Koch, 1997). In such process the elemental blended powders are continuously welded and fractured to achieve alloying at the atomic level (Suryanarayana, 2004). By milling ceramic hard phase and metallic binder, refined composite powders are obtained (He et al; 1998, 2002). By varying the milling conditions, different sizes of the hard phase can be adjusted. Two different terms are most 
commonly used to describe the processing of powder particles in high-energy ball mills. Mechanical alloying describes the process when mixtures of powders (of different metals or alloys/compounds) are milled together. Thus, if powders of pure metals A and B are milled together to produce a solid solution (either equilibrium or supersaturated), intermetallic, or amorphous phase, the process is referred to as MA. Material transfer is involved in this process to obtain a homogeneous alloy. When powders of uniform (often stoichiometric) composition, such as pure metals, intermetallics, or pre-alloyed powders, are milled in a high-energy ball mill, and material transfer is not required for homogenization, the process has been termed mechanical milling (MM).

Mechanical alloying is a complex process involving optimization of a number of process variables to achieve the desired product phase, microstructure, and/or properties. For a given composition of the powder, some of the important variables that have an important effect on the final constitution of the milled powder are as: type of mill, milling container, milling energy/speed, milling time, size distribution of grinding medium, ball-to-powder weight ratio (BPR), extent of vial filling, milling atmosphere, process control agent (PCA), and temperature of milling. For more information about the milling parameters and the effect of these variables on the final product, refer to the book entitled "Mechanical Alloying and Milling" was written by C. Suryanarayana (Suryanarayana, 2004).

Powder particle size and morphology of the feedstock powder influence the melting conditions during spraying and therefore determine coating and microstructure formation. To obtain particles with dissimilar morphologies, powders can be produced by different processing routes including high-energy milling, spray drying and sintering, as depicted by Eigen et al; in Fig. 3. Route A includes milling under agglomerating conditions. If sufficient agglomeration is obtained directly in the milling process, further powder refinement only requires sieving to cut off larger size fractions. In an effort to minimize milling time, milling can therefore, also be stopped at an earlier state followed by a classifying process to yield particle sizes in the sprayable range, thus saving time and energy (route B). In a third route $\mathrm{C}$, high-energy ball milling may be combined with spray drying and sintering, leading to spherical and more open powder morphologies with a finer and more homogeneous phase distribution as compared to conventional feedstock powders (Eigen et al; 2003, 2005).

\section{Advanced materials and related thermal spray coatings}

In thermal spraying technology, molten or semi-molten powders are deposited onto a substrate to produce a coating. The microstructure and properties of the materials depend on the thermal and momentum characteristics of the impinging particulate (Pawlowski, 2008), which are determined by both the spraying methodology and the type of feedstock materials employed. Various coatings are deposited on the surface of a substrate to either provide or improve the performance of materials in industrial applications. Nanostructured and advanced materials are characterized by a microstructural length scale in the 1-100 nm. More than $50 \mathrm{vol}$ \% of atoms are associated with grain boundaries or interfacial boundaries when the grain is small enough. Thus, a significant amount of interfacial component between neighboring atoms associated with grain boundaries contributes to the physical and mechanical properties of nanostructured materials. Using nanostructured or advanced feedstock powders, thermal spraying has allowed researchers to generate coatings having 
higher hardness, strength, and corrosion resistance than the conventional counterparts (He et al; 2002).

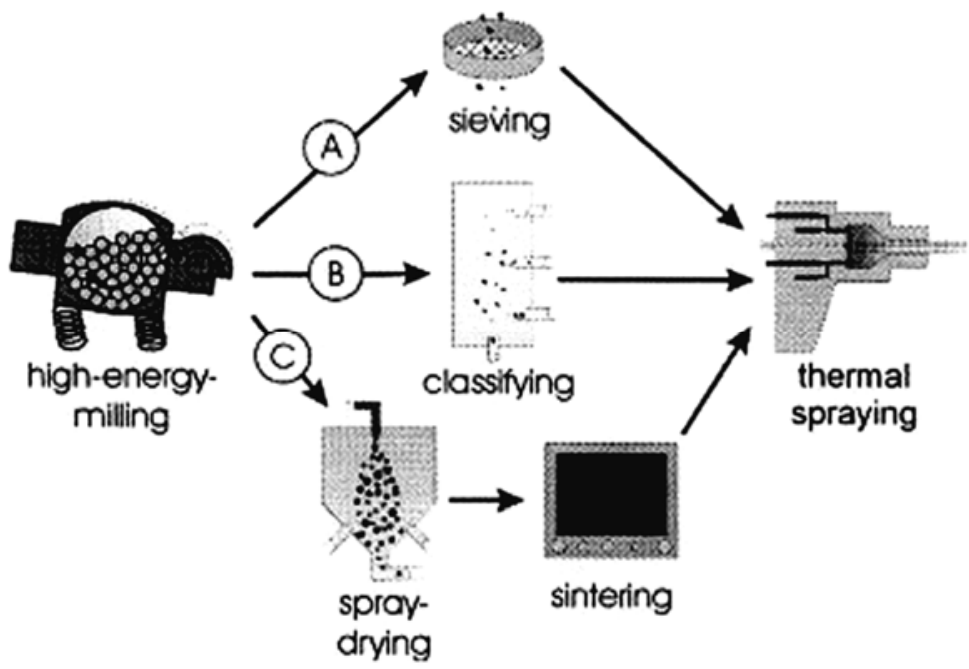

Fig. 3. Schematic of process routes for the production of thermal spray feedstock powders (Eigen et al; 2003).

\subsection{Intermetallic compounds}

Self-bonding materials are widely used in the thermal spray industry. Because the coating to substrate bond is often the weakest link in thermal spray coating systems, the ability of selfbonding materials to give a tenacious, reliable bond to the substrate greatly enhances the adhesion and therefore the performance of entire coating systems. While a number of these materials exist, the most popular and widely used is the nickel-aluminium powders (Pawlowski, 2008; Steenkiste et al; 2002). The reason for the good adhesion of these powders on non-pretreated surfaces (preheated only at $80-100^{\circ} \mathrm{C}$ to eliminate condensation), is the nascent heat evolved by the exothermic reaction of $\mathrm{Ni}$ and $\mathrm{Al}$ which form nickel-aluminide during spraying (Deevi et al; 1997). Different results are available concerning the completeness of the aluminide reaction during the spraying, and the type of aluminide formed. Phase composition in coatings sprayed using Ni-Al powders of different compositions with vacuum plasma spray (VPS) and air plasma spray (APS) methods were studied by Sampath et al. (Sampath et al; 1990). They described that the VPS coatings have a microstructure that results from the reaction between $\mathrm{Ni}$ and $\mathrm{Al}$, and APS coatings contain the $\mathrm{Ni}$ and $\mathrm{Al}$ oxides from air or contain $\mathrm{Al}_{2} \mathrm{O}_{3}$ together with a solid solution of $\mathrm{Al}$ in $\mathrm{Ni}(\mathrm{a}-$ $\mathrm{Ni}$ ). It might be concluded that the spraying atmosphere (especially its oxygen content) has a major effect on final microstructure. The chemical reactions resulting directly in the coating phase composition take place during the particle flight in a flame (Chung et al; 2002; Hearley et al; 2000).

Movahedi et al; synthesised a thermal spray $\mathrm{Ni}-10 \mathrm{wt} \% \mathrm{Al}$ powder consists of an aggregate containing the two components consisting of an alternative nickel and aluminium layers by 
low energy ball mills, such as tumbler, whereby the components are milled together for extended periods to form homogeneous powders (Movahedi et al; 2005a, 2009). Such a layered structure can be readily produced by mechanical alloying of elemental powders (Eigen et al; 2003). A rigid bonding between the particles is caused by a cold welding when mechanical energy is applied to different kinds of powders (Chen et al; 1999). Such binderless composite powders, which can be thermally sprayed to form coatings on various substrates, are suitable for using in a thermal spray process (Maric et al; 1996).

Fig. 4. shows $\mathrm{XRD}$ patterns of $\mathrm{Ni}-10 \mathrm{wt} \% \mathrm{Al}$ powders after different low energy milling times. X-ray diffraction patterns include only elemental $\mathrm{Ni}$ and $\mathrm{Al}$ peaks without any identification of oxides or intermetallic phases. In contrast, some researchers (Enayati et al; 2004) reported that ball milling of Ni75Al25 powder mixture in a high-energy ball mill (i.e., planetary), led to the formation of a $\mathrm{Ni}(\mathrm{Al})$ solid solution that transformed to nickel aluminide on further milling. The extent of plastic deformation of powder particles, the local increase of temperature, and also the increase in the density of lattice defects in low energy ball mills and therefore the mass transport by diffusion are smaller compared to those in high-energy ball mills, making it impossible to obtain nickel aluminide phase (Boldyrev \& Tkacova, 2000; El-Eskandarany, 2001).

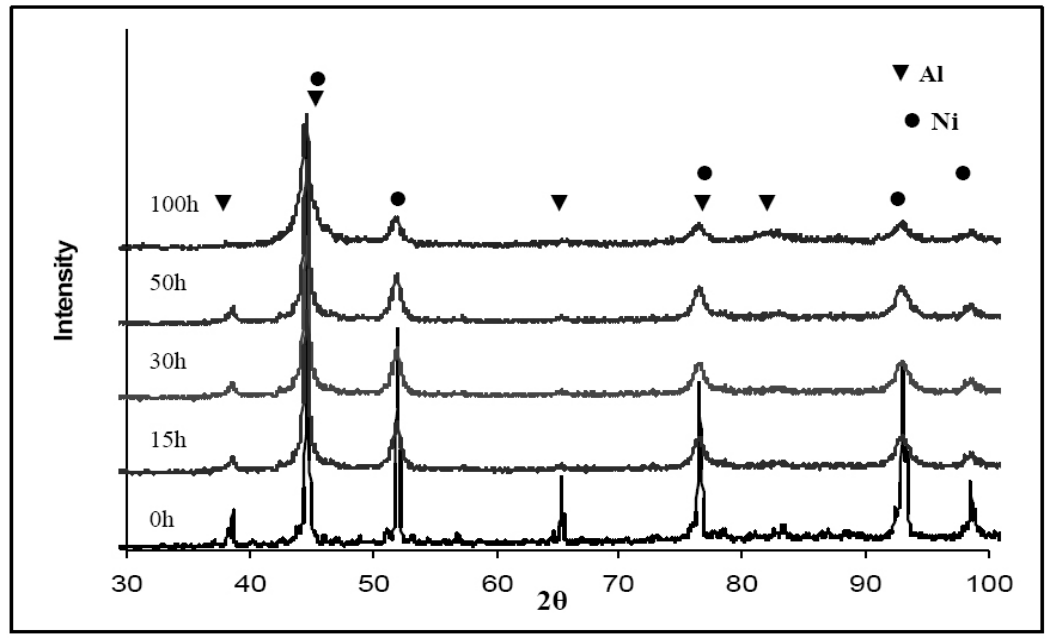

Fig. 4. X-ray diffraction patterns of $\mathrm{Ni}-10 \mathrm{wt} \% \mathrm{Al}$ composite powders as received and after different milling times (Movahedi et al; 2009).

It is noted that $\mathrm{Ni}$ and $\mathrm{Al}$ XRD peaks have a lower intensity and higher width than those of initial powders due to the refinement of the crystallite size as well as an increase in the nonuniform internal strain of $\mathrm{Ni}$ and $\mathrm{Al}$ crystal lattices. Fig. 5. shows cross-sectional images of powder particles after different milling times. At the early stage of ball milling (10h), the Al particles were flattened and cold welding to the Ni particles. After 20h of low energy mechanical milling, the Ni particles also deformed plastically, and a typical lamellar structure consisting of pure $\mathrm{Al}$ and $\mathrm{Ni}$ layers with a layer thickness of $\sim 10 \mu \mathrm{m}$ was formed (white areas are $\mathrm{Ni}$ and black areas are $\mathrm{Al}$ ). On continuous ball milling, the layered structure refined so that after $35 \mathrm{~h}$ of milling time the average layer thickness was $\sim 5 \mu \mathrm{m}$. 


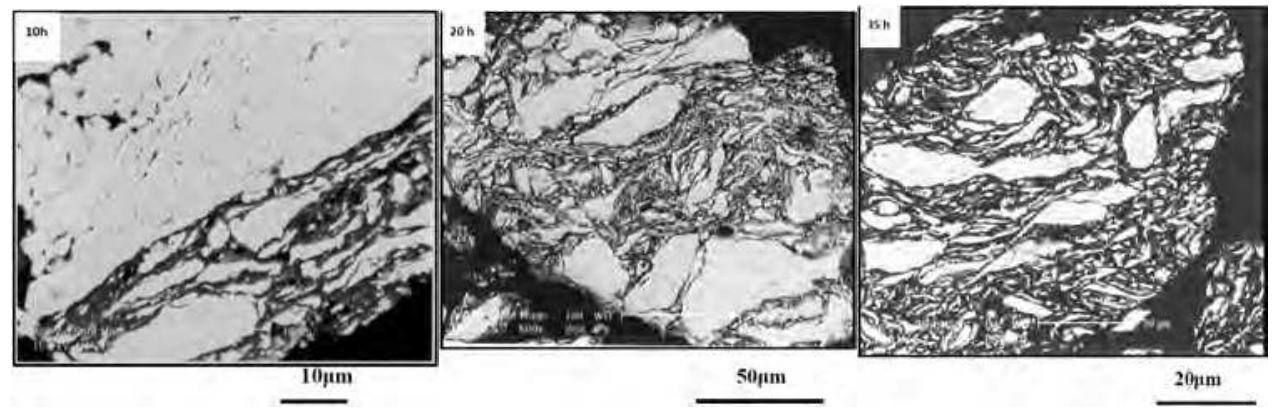

Fig. 5. Cross-sectional SEM images of $\mathrm{Ni}-10 \mathrm{wt}-\% \mathrm{Al}$ composite powders after different milling times (Movahedi et al; 2005a, 2009).

Fig. 6. plots the average particle size of the powders on milling time. As milling time increased to $20 \mathrm{~h}$, the average $\mathrm{Ni}-10 \mathrm{wt}-\% \mathrm{Al}$ particle size increased and reached to the maximum value of $300 \mu \mathrm{m}$. For milling times longer than $20 \mathrm{~h}$, the average particle size decreased and finally approached a constant value of $5 \mu \mathrm{m}$ after $100 \mathrm{~h}$ of milling time. In addition, the powder particle size becomes more uniform by increasing the milling time.

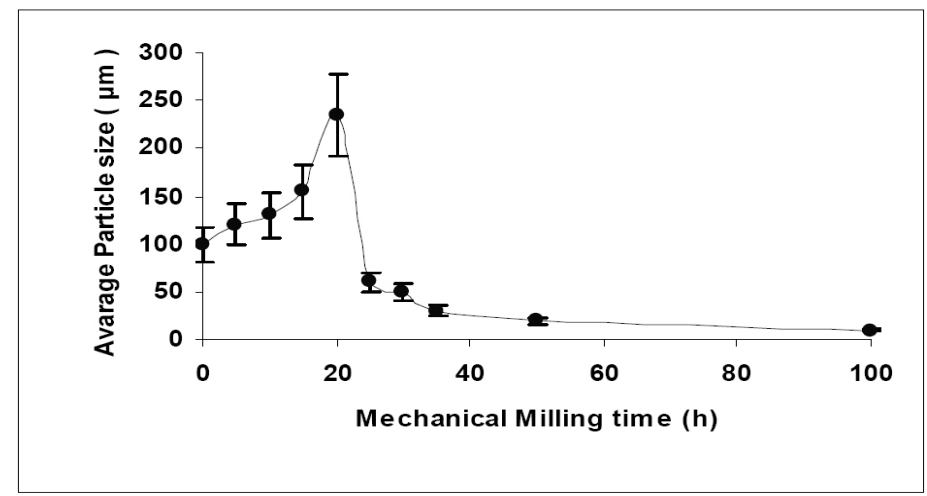

Fig. 6. Average particle size of $\mathrm{Ni}-10 \mathrm{wt} \% \mathrm{Al}$ composite powders versus milling time (Movahedi et al; 2009).

The changes of powder particle size during ball milling are caused by fracture and cold welding of $\mathrm{Ni}$ and $\mathrm{Al}$ powder particles during milling. The smaller particles grow while the larger ones fracture. A rigid bonding between the particles is caused by a welding when mechanical energy is applied to different kinds of powders (Chen et al; 1999). During milling the ingredients of the powder, mixtures are reduced in size and brought into intimate contact by flattening and crushing the particles, welding them together, and repeating the process again and again. The resultant powders essentially consist of a homogeneous and uniform distribution of the initial component within the powder particles (Maric et al; 1996). The particle size distribution of the powders has a major effect on quality and morphology of thermal spray coatings. It is generally accepted that the optimum particle size for thermal spray powders is within the range $35-100 \mu \mathrm{m}$. These powders are large enough to be easily fed from simple hoppers but small enough for efficient melting to 
occur. Under a given set of plasma conditions, there is likely to be an optimum size of particle that will be melted in the plasma, transported with sufficient momentum, and subsequently deposited. Smaller particles will lose velocity or may be vaporised with subsequent loss of spraying efficiency, whereas large particles will be incompletely melted and will produce a coating with large pore and low strength. In addition, the particle size significantly affects particle temperature and speed during flight, which subsequently influences the properties of the coating (He \& Schoenung, 2002). Movahedi et al; reported that the Ni-10 $\mathrm{wt} \% \mathrm{Al}$ powders made by low energy ball milling have a microstructure consisting of alternative $\mathrm{Ni}$ and $\mathrm{Al}$ layers and include high defect density such as dislocations and vacancies. Therefore, the exothermic reaction between $\mathrm{Ni}$ and $\mathrm{Al}$ layers during flight in plasma spray process, readily occurs which subsequently enhances the bonding strength.

Fig. 7. shows the XRD pattern of plasma spray coating. It can be seen that plasma spray coating include NiAl intermetallic phase along with a-Ni solid solution. Significant feature of powders produced by mechanical milling is that a lamellar structure consisting of pure $\mathrm{Al}$ and $\mathrm{Ni}$ layers forms during milling process. This structure provides a large $\mathrm{Ni} / \mathrm{Al}$ interfaces for exothermic reaction to occur during flight in plasma spraying. The incomplete $\mathrm{Ni}$ and $\mathrm{Al}$ reaction is due to the rapid heat losses of powder particles during thermal spraying (Movahedi et al; 2005b, 2009).

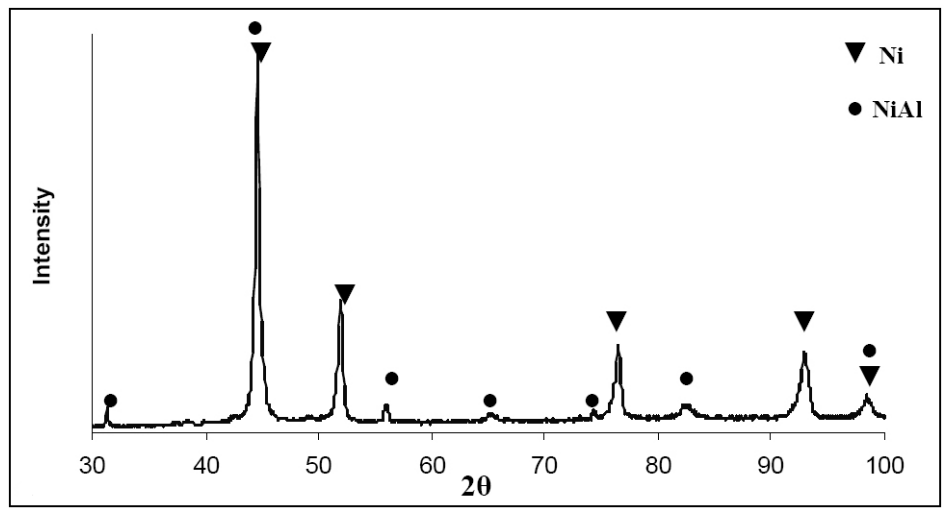

Fig. 7. X-ray diffraction patterns of $\mathrm{Ni}-10 \mathrm{wt} \% \mathrm{Al}$ plasma spray coatings (Movahedi et al; 2009).

Fig. 8. shows the cross-sectional microstructure images of the plasma spray coatings. The shape of the pores suggests that they were formed due to the expansion of trapped air when the impacting particles were still molten. Cavities and pores are formed between the individual particles in the sprayed coatings because inter-particle diffusion is limited and particle flow is hindered during the splat cooling process (Movahedi et al; 2009).

$\mathrm{Ni}-\mathrm{Al}$ intermetallics are being recognized as high temperature structural materials because of their excellent oxidation resistance, high thermal conductivity, low density, and high melting point (Stoloff etal; 2000). Research on nickel aluminides has been expanded during the last 30 years, not only as bulk materials, but also as coatings. Studies have indicated that nickel aluminide alloys have significant potential in wear applications as wear properties of 
carbon steel parts can be significantly improved by applying nickel aluminide coating (Goldenstein et al; 2004; Houben et al; 1973; Knotek et al; 1973; Rickerby et al; 1991). The possible applications of Ni-Al include; gas turbine engine, rotor blades, and stator vanes, however, low ductility at ambient temperature is the major limitation of this material. A number of attempts have been made to overcome this drawback such as nanocrystallization of structure which may transform nominally brittle compound into the ductile material (Morsi, 2001). One of the synthesis methods of nanocrystalline $\mathrm{Ni}$-Al intermetallic compounds is high energy mechanical alloying. Two different mechanisms, via a rapid explosive reaction or through a gradual diffusion, were found for $\mathrm{Ni}-\mathrm{Al}$ formation during MA (Atzmon, 1990; Enayati et al; 2008; Mashreghi et al; 2009). The powder prepared by MA can be deposited on surfaces of engineering parts using different thermal spraying techniques including plasma spray and, high velocity oxy fuel (HVOF) process. There are limited investigations in the literature concerning thermally sprayed coatings of nickel aluminides. Hearley et al. used inert gas atomized and reaction sintered Ni-30 wt.\% Al powders to prepare NiAl intermetallic coatings by HVOF thermal spraying. They reported that a spherical inert gas atomized powder with narrow particle size range between 15 and $45 \mu \mathrm{m}$ produced coatings of better quality. Their results also showed that both the fuel and oxygen flow rates influence the coating deposition characteristics and properties (Hearley et al; 1999, 2000).

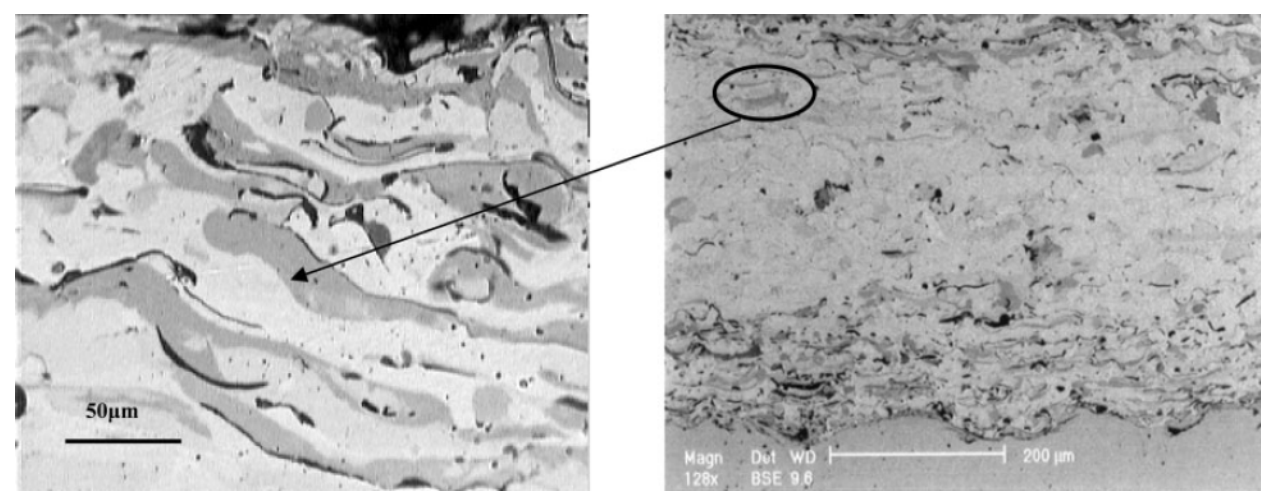

Fig. 8. Cross-sectional SEM images of $\mathrm{Ni}-10 \mathrm{wt} \% \mathrm{Al}$ plasma spray coating at different magnifications (Movahedi et al; 2005b, 2009).

Fig. 9. shows the XRD patterns of Ni50Al50 powder mixture as-received and after 60, 90, and 120 min of high energy milling times. The XRD patterns of the as-received Ni50Al50 powder showed diffraction peaks of the crystalline $\mathrm{Ni}$ and Al. Increasing milling time to 60 min led to the disappearance of the $\mathrm{Ni}$ and $\mathrm{Al}$ peaks, while $\mathrm{NiAl}$ peaks began to appear. Complete transformation of elemental $\mathrm{Ni}$ and $\mathrm{Al}$ powder mixture to the NiAl intermetallic phase appeared to occur after $90 \mathrm{~min}$ of high energy ball milling. This result shows that the reaction between $\mathrm{Al}$ and $\mathrm{Ni}$ is promoted by the extensive $\mathrm{Ni} / \mathrm{Al}$ interface areas as well as the short circuit diffusion paths provided by the large number of defects such as dislocations and grain boundaries introduced during high energy ball milling (Enayati et al; 2011). Hu et al. reported that complete transformation of $\mathrm{Ni}+\mathrm{Al}$ to $\mathrm{NiAl}$ compound during MA occurred after $240 \mathrm{~h}$ which is much longer than MA time obtained in the work of Enayati, et al. This discrepancy can be due to the different mill machines used. 


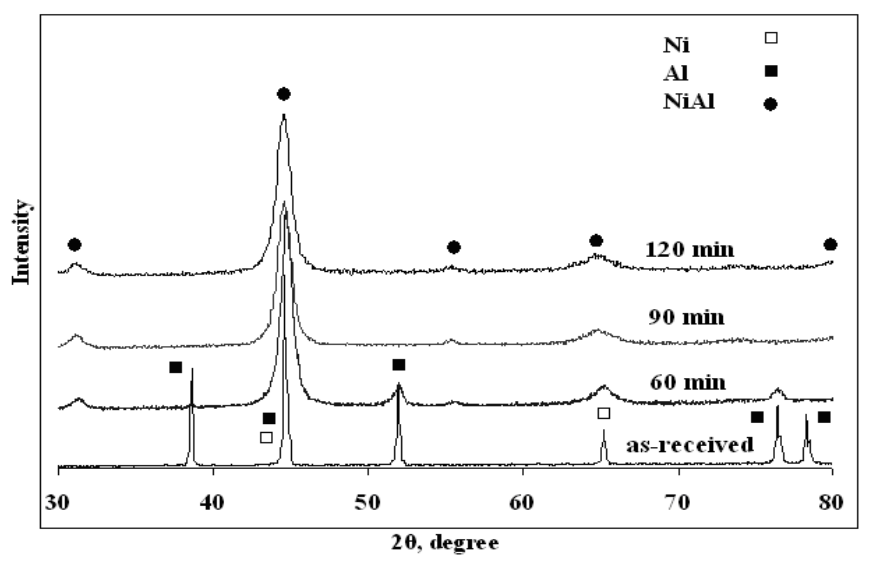

Fig. 9. The development of NiAl intermetallic compound from Ni50Al50 powder mixture during mechanical alloying (Enayati et al; 2011).

The XRD patterns of the as-milled powder for $90 \mathrm{~min}$ and as-deposited coatings prepared with two sets of spray parameters (Table 1) are presented in Fig. 10. Besides NiAl main peaks several additional small, broad peaks can be observed on the XRD patterns of the coatings. These broad peaks were identified as $\mathrm{Ni}$ and $\mathrm{Al}_{2} \mathrm{O}_{3}$ phases. Enayati, et al. suggested that oxidizing of $\mathrm{Al}$ and subsequent separation of $\mathrm{Ni}$ occurred as $\mathrm{NiAl}$ particles are subjected to the high temperature (typically $3000{ }^{\circ} \mathrm{C}$ ) during $\mathrm{HVOF}$ spraying. The intensity of $\mathrm{Ni}$ and $\mathrm{Al}_{2} \mathrm{O}_{3}$ peaks are higher in coating II as the fuel/oxygen ratio increases. It means that a higher fuel/oxygen ratio results a higher flame temperature and therefore more oxidation during HVOF processing.

\begin{tabular}{lcc}
\hline \multirow{2}{*}{ HVOF Parameters } & \multicolumn{2}{c}{ Condition } \\
\cline { 2 - 3 } & I & II \\
\hline Oxygen flow rate $(\mathrm{l} / \mathrm{min})$ & 830 & 830 \\
Fuel flow rate $(\mathrm{ml} / \mathrm{min})$ & 210 & 240 \\
Fuel/oxygen volume ratio & 0.025 & 0.029 \\
Spray distance $(\mathrm{mm})$ & 360 & 360 \\
Powder rate $(\mathrm{g} / \mathrm{min})$ & 80 & 80 \\
Number of passes & 3 & 3 \\
\hline
\end{tabular}

Table 1. HVOF Spraying parameters for NiAl coatings (Enayati et al; 2011).

Fig. 11. shows the cross-sectional SEM images of the coatings at several magnifications. The coating exhibits a typical splat-like and layered morphology due to the deposition and resolidification of molten or semi-molten droplets. The light and dark gray layers are Ni-rich and Al-rich phases, respectively, which are consistent with the work of Movahedi, et al. (Movahedi et al; 2005B, 2009). Enayati, et al. suggested that an improved in uniformity of microstructure was observed for coating II due to the higher fuel flow rate and flame temperature (Enayati et al; 2011). 


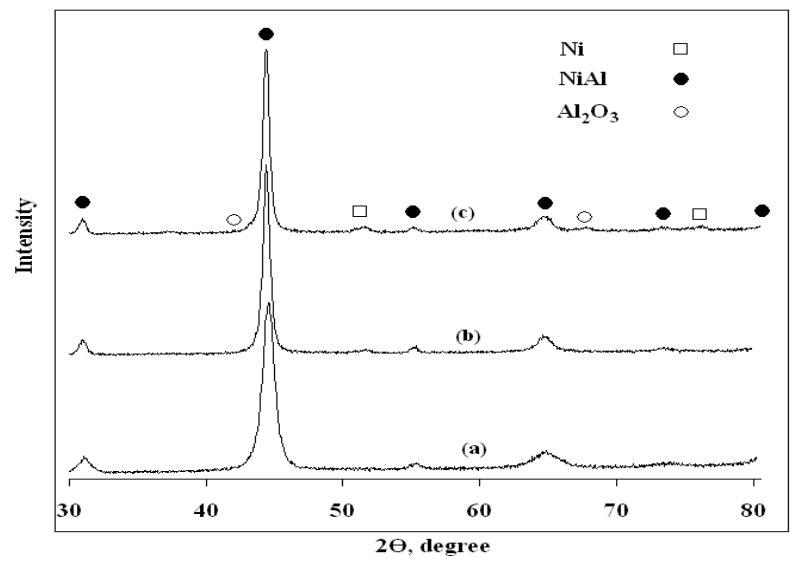

Fig. 10. The XRD patterns of as-milled NiAl powder for $90 \mathrm{~min}$ (a) and as-deposited coatings prepared at conditions I (b) and II (c) (Enayati et al; 2011).
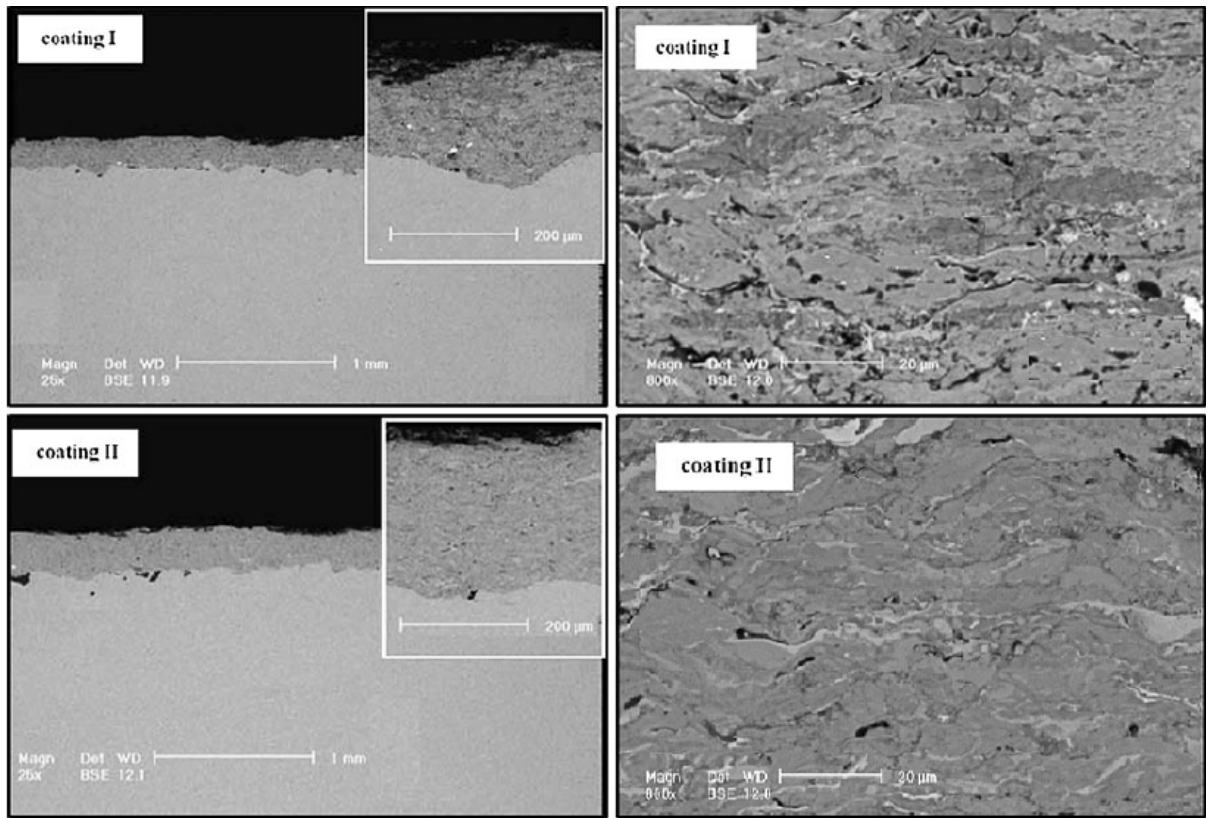

Fig. 11. Cross-sectional microstructure of the HVOF coatings (Enayati et al; 2011).

A dense $\mathrm{Ni} / \mathrm{Al}$ alloy coating was deposited by cold spraying using a mechanically alloyed powder was reported by Zhang, et al (Zhang et al; 2008). Fig. 12. shows typical SEM images of cross-sectional microstructure of cold-sprayed $\mathrm{Ni} / \mathrm{Al}$ alloy coating using milled $\mathrm{Ni} / \mathrm{Al}$ alloy powder. It was observed that the coating exhibited a dense microstructure and some apparent thick layers with a white contrast appeared on the coating microstructure. 

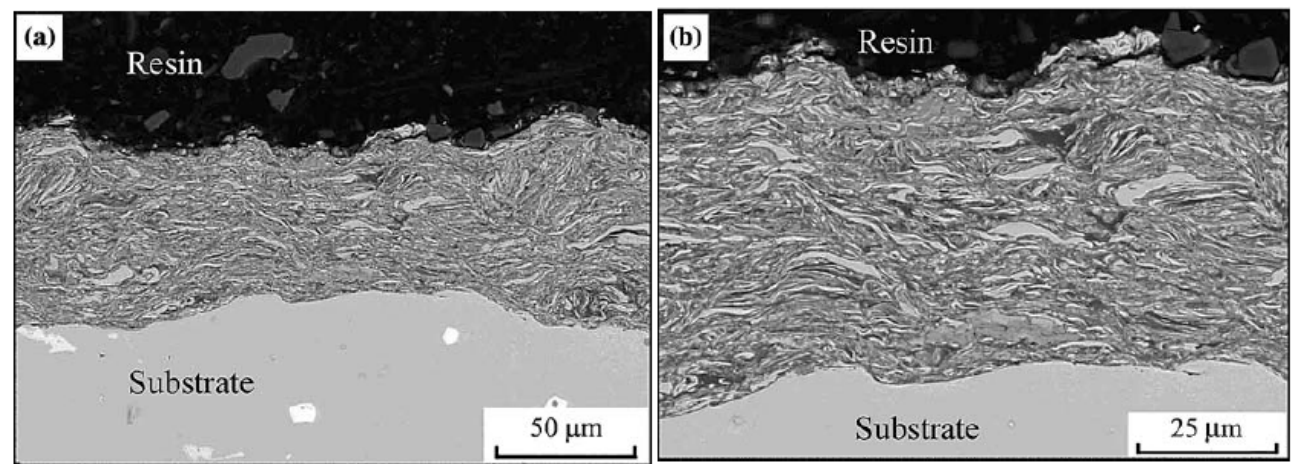

Fig. 12. Cross-sectional microstructure of cold-sprayed Ni/Al alloy coating observed at different magnifications (Zhang et al; 2008).

XRD patterns of the as-sprayed coating and feedstock powder are shown in Fig. 13. Only the peaks of nickel and aluminum were identified in XRD pattern of the ball-milled powder. It is clear that the XRD pattern of the cold spray coating is almost the same as that of the milled powder. This fact indicates that the coating and feedstock exhibited the same phase structure and no oxide was identified in the powder and the coating by XRD. In cold spraying, the particle deposition takes place in a solid state. Consequently, the lamellar structure of the milled powder will be completely retained in the coating, giving a unique effect on the microstructure and properties of the cold-sprayed coating. According to EDS analysis of the coating, was mentioned by Zhang, et al. the thicker layer in a white contrast was a Ni-rich phase and the fine lamella was a Ni-Al solid solution with high-Al content.

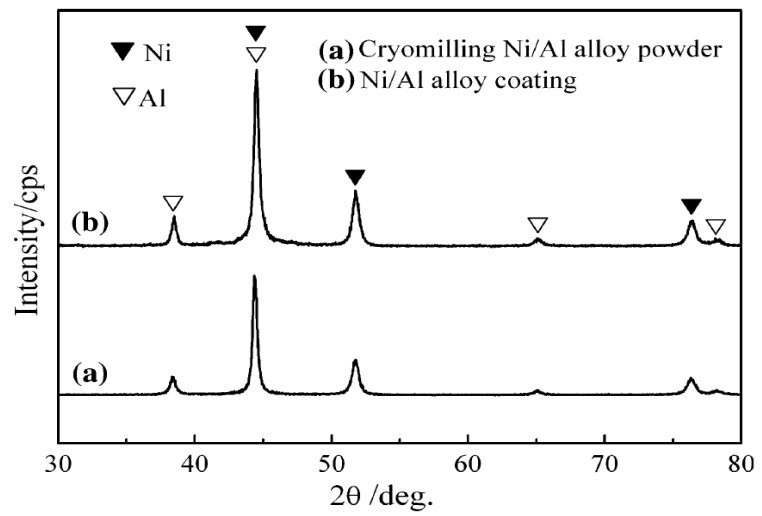

Fig. 13. XRD patterns of the Ni/ Al feedstock powder fabricated by ball milling and the as-cold spray coating (Zhang et al; 2008).

The XRD patterns of annealed $\mathrm{Ni} / \mathrm{Al}$ cold spray coatings are shown in Fig. 14. After annealing treatment at $500^{\circ} \mathrm{C}$ for $3 \mathrm{~h}, \mathrm{Ni}$ and $\mathrm{Al}$ peaks completely disappeared and peaks corresponding to $\mathrm{Ni}_{2} \mathrm{Al}_{3}$ and $\mathrm{NiAl}$ appeared (Fig. 14a). With annealing temperature rising to $600^{\circ} \mathrm{C}$, it can be found from Fig. 14 (b) that $\mathrm{NiAl}$ became the main phase, only minor $\mathrm{Ni}_{2} \mathrm{Al}_{3}$ exists. As the temperature was raised to $850^{\circ} \mathrm{C}$, the diffraction peaks of $\mathrm{Ni}_{2} \mathrm{Al}_{3}$ disappeared 
completely, and only diffraction peaks of NiAl phase were present in the XRD pattern, as shown in Fig. 14(c). This fact indicates that the annealing at temperature of higher than $850^{\circ} \mathrm{C}$ completely converts $\mathrm{Ni} / \mathrm{Al}$ alloy to $\mathrm{NiAl}$ intermetallic compound. As the temperature reached $1050^{\circ} \mathrm{C}$, no additional reaction was detected, and the $\mathrm{NiAl}$ phase was present in the coating (Fig. 14d) (Zhang et al; 2008).

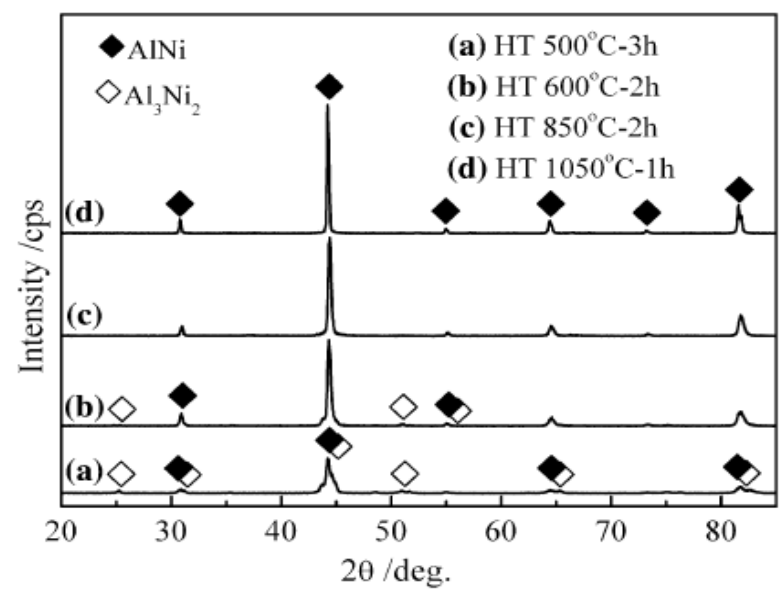

Fig. 14. XRD patterns of the $\mathrm{Ni} / \mathrm{Al}$ cold spray coatings annealed at different temperatures (Zhang et al; 2008).

\subsection{Intermetallic-ceramic and nanocomposites}

As mentioned earlier, intermetallic compounds are an important class of materials because of a combination of their high tensile strength, low density, good wear, and creep resistance. These properties have led to the identification of several potential usages including structural applications and protective coatings (Sauthoff, 1995). Two major problems that restrict the application of intermetallic compounds are poor low-temperature ductility and inadequate high temperature creep resistance. These limitations can be overcome by introducing ceramic particles as reinforcements (Morris, 1998). Originally, reinforcement phase can be introduced in the matrix by two routs namely ex-situ addition of reinforcement particles and in-situ formation of reinforcement phase via a displacement reaction which both phase (Intermetallic and ceramic) are formed during ball milling. A rigid bond between the particles is created by cold welding when mechanical energy is applied to powder particles (Chen et al; 1999). Incorporation of hard second phases into an intermetallic composite (IC) matrix is a strategy for effective high-temperature strengthening, creating an intermetallic matrix composite (IMC). Recently, a great deal of work has been done on intermetallic matrix composites (IMCs). Various continuous or discontinuous ceramic reinforcements such as $\mathrm{SiC}, \mathrm{Al}_{2} \mathrm{O}_{3}, \mathrm{TiB}_{2}$, and $\mathrm{TiC}$ were explored to obtain increased high temperature strength and better creep resistance, together with adequate ductility and toughness (Inoue et al; 2000). Among these reinforcements, SiC fibers were commercialized for use in IMCs. The $\mathrm{SiC}$ reinforcements were added into different nickel aluminide matrices by reaction synthesis, mechanically alloying, and sintering (powder metallurgy) (Lee et al; 2001; Zhang et al; 2004) to improve oxidation and mechanical properties and the workability 
of the matrices. Hashemi et al. reported the synthesis of nickel aluminide matrix composite coating reinforced by $\mathrm{SiC}$ particulates that was fabricated by the plasma spraying of Ni-Al$\mathrm{SiC}$ powder prepared by low energy ball milling. The cross-sectional SEM image of the powder particles after $15 \mathrm{~h}$ of milling time is presented in Fig. 15. As it can be shown the SiC particles were incorporated into the $\mathrm{Ni} / \mathrm{Al}$ powder particles.

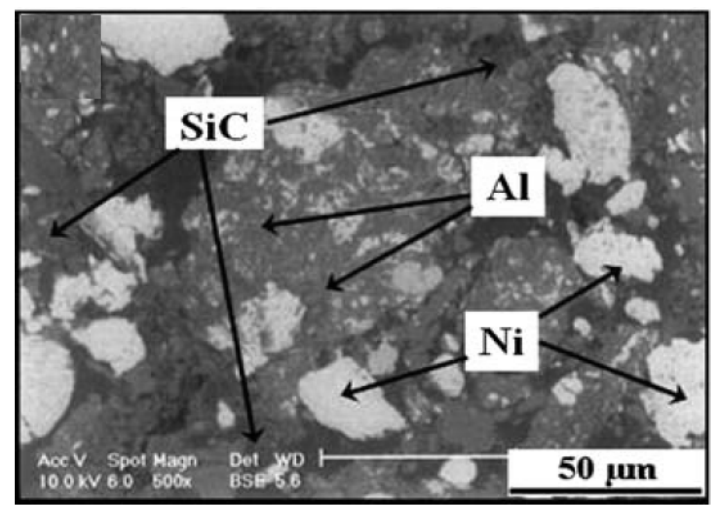

Fig. 15. Cross-sectional SEM images of Ni-Al-SiC powder particles produced by low energy ball milling (Hashemi et al; 2009).

The formation of Ni-Al intermetallic compounds required a long time and a high temperature for the diffusion of $\mathrm{Al}$ and $\mathrm{Ni}$. In thermal spray processes, the temperature is high enough for diffusion, but the exposure time of powders to plasma flame is too short. After powder deposition on the substrate, the high-temperature diffusion and therefore the $\mathrm{Ni}-\mathrm{Al}$ reaction is stopped (Houben et al; 1973; Sampath et al; 2004). Hashemi et al, suggested that by increasing the plasma spray distance the diffusion time increased, while by increasing current density the plasma flame temperature increased. These two parameters determine the content of intermetallic compound in the coatings. They also mentioned that by increasing the current intensity from 600 to $700 \mathrm{~A}$, the relative amount of $\mathrm{Ni}$ decreased while that of $\mathrm{Ni}_{2} \mathrm{Al}_{3}$ phase increased, whereas by increasing the current intensity from 700 to $800 \mathrm{~A}$, a reverse trend was observed. On the other hand, the increased current density will increase the velocity of the powder flow rate, thus declining the dwelling time of the powder particles and further decreasing the amount of $\mathrm{Ni}_{2} \mathrm{Al}_{3}$. In this approach, powder particles experience lower heat, which eliminates the diffusion of $\mathrm{Ni}$ and $\mathrm{Al}$ and therefore the development of $\mathrm{Ni}-\mathrm{Al}$ compounds. The cross-sectional microstructure of as-sprayed coating in optimum spray condition is shown in Fig. 16. (Hashemi et al; 2009).

Horlock, et al. synthesised a reactive powder having a nominal composition of 50wt.\% Ni(Cr)-40wt.\%Ti-10wt.\%C with the planar-type ball milling. They reported that the reaction to produce $\mathrm{TiC}$ is initiated within individual powder particles during $\mathrm{HVOF}$ spraying, leading to the formation of a coating containing TiC particles within a nanocomposite Ni-rich matrix. The TiC particles were found in the coating (Fig. 17) on the order of 50 to $200 \mathrm{~nm}$ in size. The Low-magnification SEM image of a cross section through an HVOF-sprayed coating shows the characteristic layered morphology with little porosity as well as the nanoscale $\mathrm{TiC}$ grains (arrowed), which are embedded in a light contrast metallic matrix. 

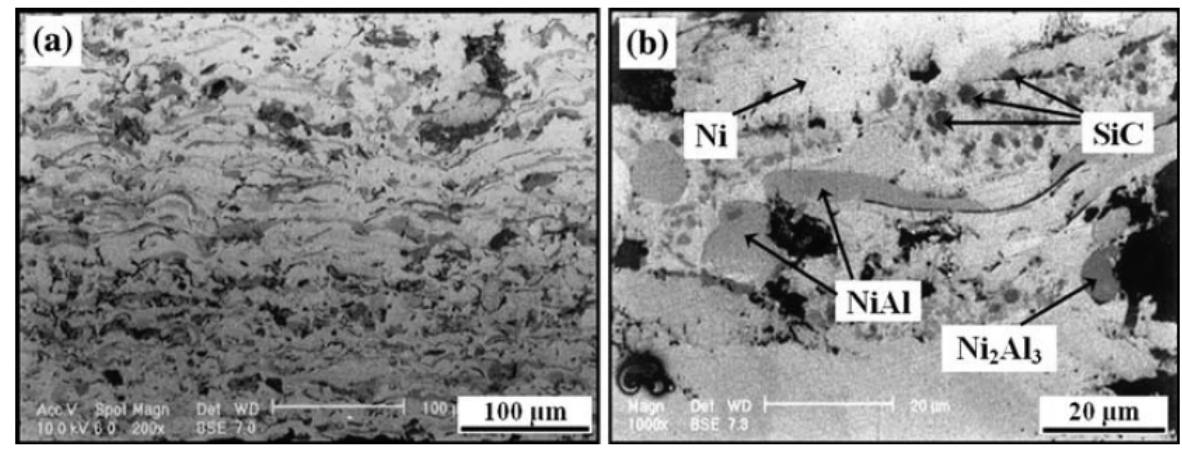

Fig. 16. Cross-sectional SEM images of plasma spray Ni-Al-SiC coating at different magnification (Hashemi, 2009).

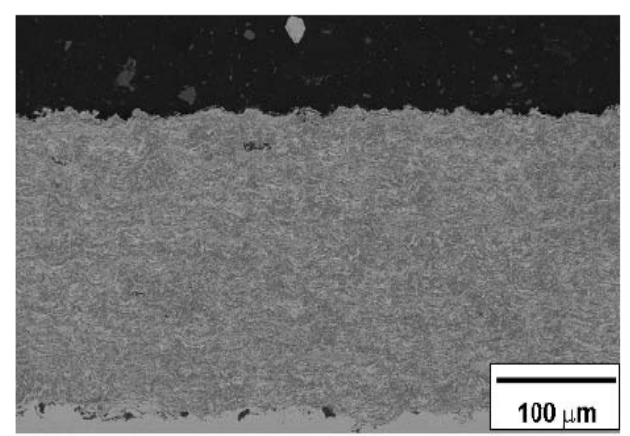

(a)

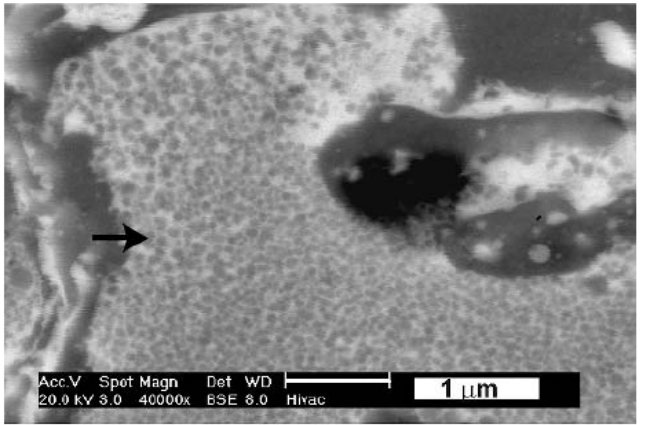

(b)

Fig. 17. (a) Low-magnification (b) high-magnification BSE image of a region from (a) of a cross section through an HVOF-sprayed $\mathrm{Ni}(\mathrm{Cr})-\mathrm{TiC}$ coating (Horlock et al; 2005).

In Horlock's work a pre-alloyed $\mathrm{Ni}(\mathrm{Cr})$ powder was used to produce a metallic matrix with the potential to resist corrosion and high-temperature oxidation, while $\mathrm{TiC}$ is a ceramic with high hardness and chemical stability. They also purposed that the final powder microstructure contains $\mathrm{Ti}, \mathrm{Ni}(\mathrm{Cr})$, and $\mathrm{C}$ all embedded in the same particle, there is a decreased possibility of fresh $\mathrm{Ti}$ surfaces being in contact with free $\mathrm{C}$. Consequently, the possibility of $\mathrm{Ti}$ oxidation of $\mathrm{TiC}$ is greatly diminished during spraying. The XRD pattern from the as-deposited coating, shown in Fig. 18. has major peaks that can be identified as a Ni-rich solid solution phase and $\mathrm{TiC}$ as well as the smaller peaks corresponding to NiTi, $\mathrm{TiO}_{2}$, and $\mathrm{NiTiO}_{3}$ (Horlock et al; 2004).

TiC-Ni based nanocomposite powders for thermal spraying were produced by high-energy attrition and vibration mills in scale up were studied by Eigen, et al. X-ray diffraction analysis shows (Fig. 19) that the crystallite sizes of both hard phase and binder are refined with increasing milling time reaching a steady state after about $20 \mathrm{~h}$.

Correspondingly, the mixing and refining of the phases can be observed by SEM (Fig. 20). At early stage of milling (Fig. 20a), the ductile binder particles are deformed to plate-like particles while hard particles are initially pressed into the surface of the binder platelets and 
cover them. In later milling stages, densification takes place, i.e. hard phase particles are fully embedded into the matrix and the matrix is completely cold-welded (Fig. 20b). In the final stage in Fig. 20c, microstructures are characterized by carbide phase dimensions ranging from less than $20 \mathrm{~nm}$ (see Fig. 19) to about $500 \mathrm{~nm}$ (Eigen et al; 2003).

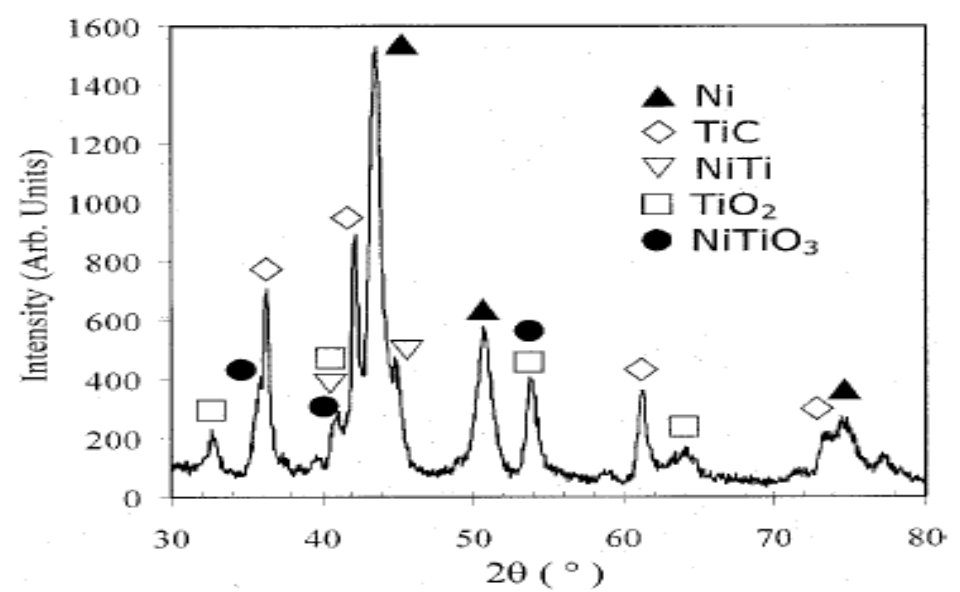

Fig. 18. The XRD pattern obtained from the HVOF as-sprayed $\mathrm{Ni}(\mathrm{Cr})$-TiC coating (Horlock et al; 2004).

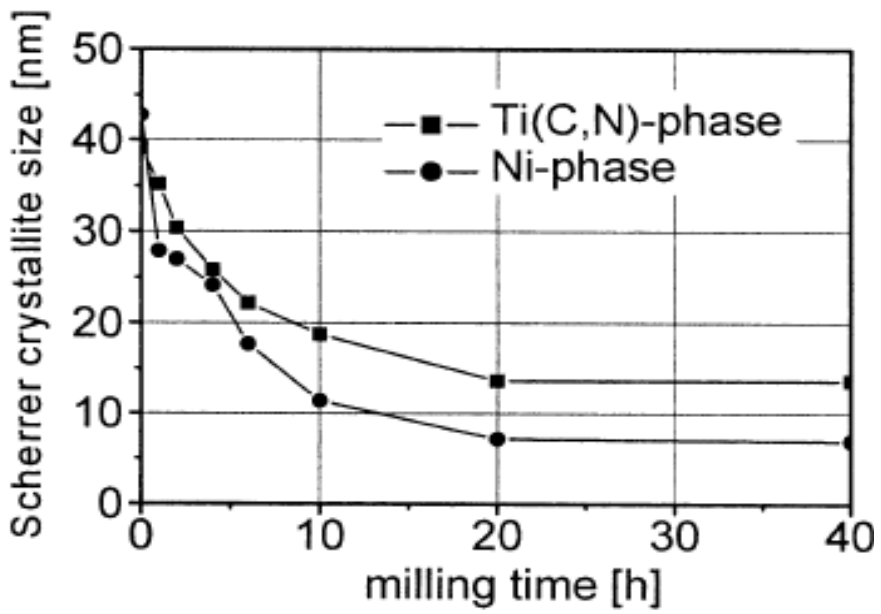

Fig. 19. Refinement of hard phase and binder phase with milling time (vibration mill, BPR 23:1). Crystallite sizes were determined using the Scherrer method (Eigen et al; 2003).

The development of a nanocomposite thermal spray powder is also studied by $\mathrm{He}$, et al. as schematically summarized in Fig. 21. In a nanocomposite powder, such as $\mathrm{Cr}_{3} \mathrm{C}_{2}-\mathrm{NiCr}$ and WC-Co, there are hard and brittle carbide particles and a tough metal binder constituent. Hard and brittle carbide particles are fractured into sharp fragments and embedded into the metal binder. The metal binder, with lower hardness, is subjected to enhanced milling from 
both the balls and hard carbide particles. As milling time increases, carbide fragments are continually embedded into the metal binder. The metal binder and the polycrystalline composite, experience continuous overlapping, cold welding, and fracturing. Finally, a polycrystalline nanocomposite powder system, in which round nanoscale carbide particles are uniformly distributed in a metal binder, is formed. As an example, Fig. 22 shows such a $\mathrm{Cr}_{3} \mathrm{C}_{2}-25$ (Ni20Cr) polycrystalline nanocomposite powder. Clearly shown that the large proportions of carbides, in the form of round particles, are uniformly distributing themselves in the $\mathrm{NiCr}$ solid solution. It is possible to use mechanical milling to synthesize other nanocomposite powder systems with a hard particle and tough binder duplex structure; examples of such systems are $\mathrm{WC}-\mathrm{NiCr}, \mathrm{TiC}-\mathrm{NiCr}, \mathrm{TiC}-\mathrm{Ti}$, and $\mathrm{SiC}-\mathrm{Al}$. The microstructures of conventional and nanostructured $\mathrm{Cr}_{3} \mathrm{C}_{2}-25(\mathrm{Ni20 \textrm {Cr }})$ coatings, examined using SEM, are shown in Fig. 23. A uniform and dense microstructure is observed in the nanostructured coatings, compared to the conventional $\mathrm{Cr}_{3} \mathrm{C}_{2}-25(\mathrm{Ni20 \textrm {Cr }})$ coating that is observed to have an inhomogeneous microstructure (He et al; 2002).
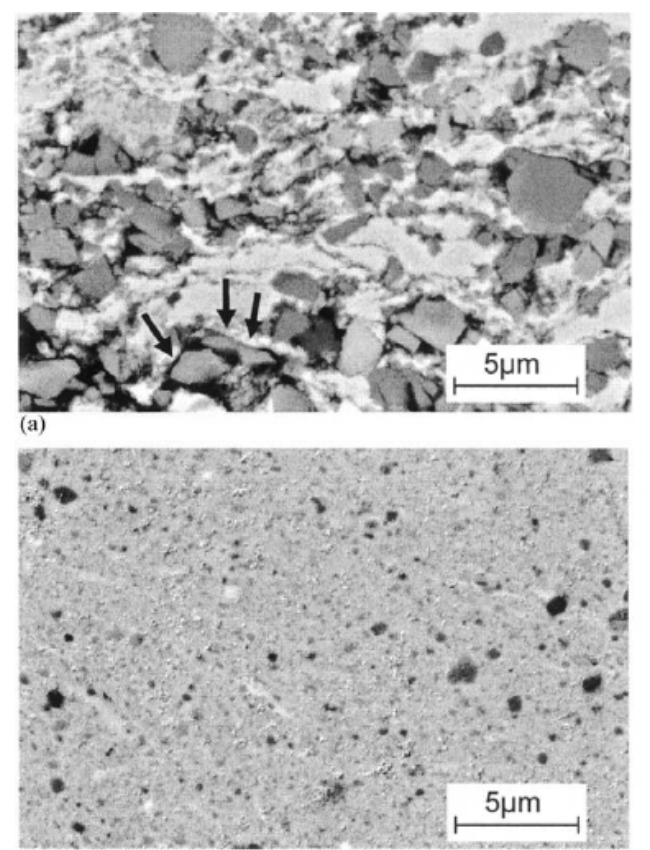

(c)

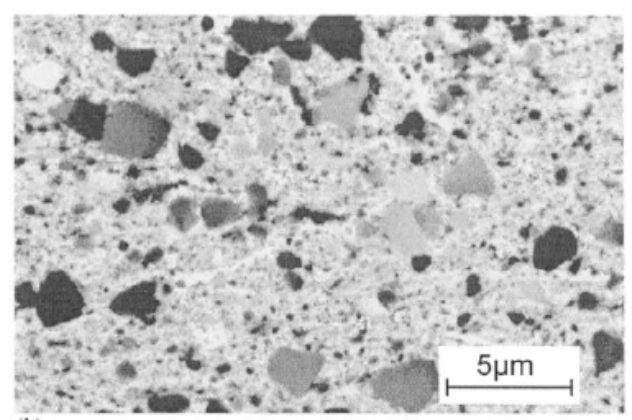

(b)

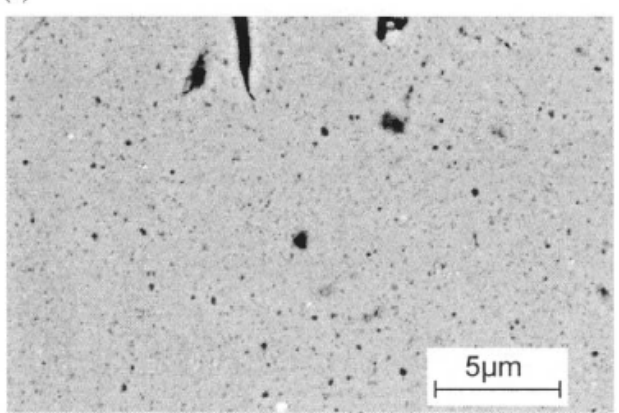

(d)

Fig. 20. Refinement of phase distribution after: (a) 2 h; (b) 10 h; and (c) $40 \mathrm{~h}$ (BPR 23:1) in the vibration mill; and (d) after $20 \mathrm{~h}$ in the attrition mill (BPR 20:1). Black arrows in (a) indicate fragments of one broken hard phase particle (Eigen et al; 2003). 


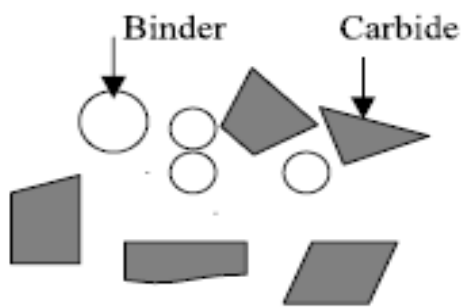

(a)

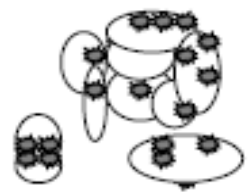

(c)

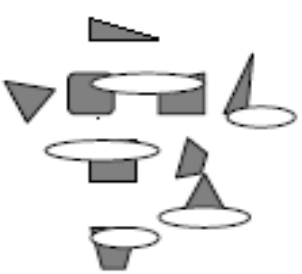

(b)

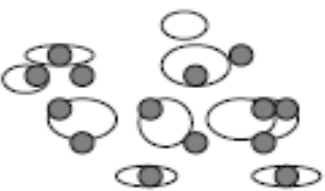

(d)

Fig. 21. Schematic diagram of milling mechanism for duplex structure powder: (a) initial stage; (b) NiCr matrix overlaps and deforms, $\mathrm{Cr}_{3} \mathrm{C}_{2}$ fractures and embed into $\mathrm{NiCr}$; (c) binders deform, fracture, and weld, carbide fracture further; and (d) nanocomposite powder (He et al; 2002).

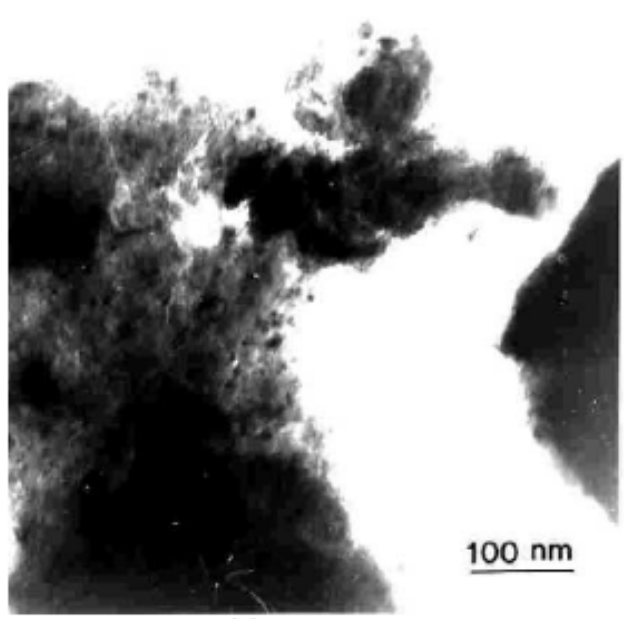

(a)

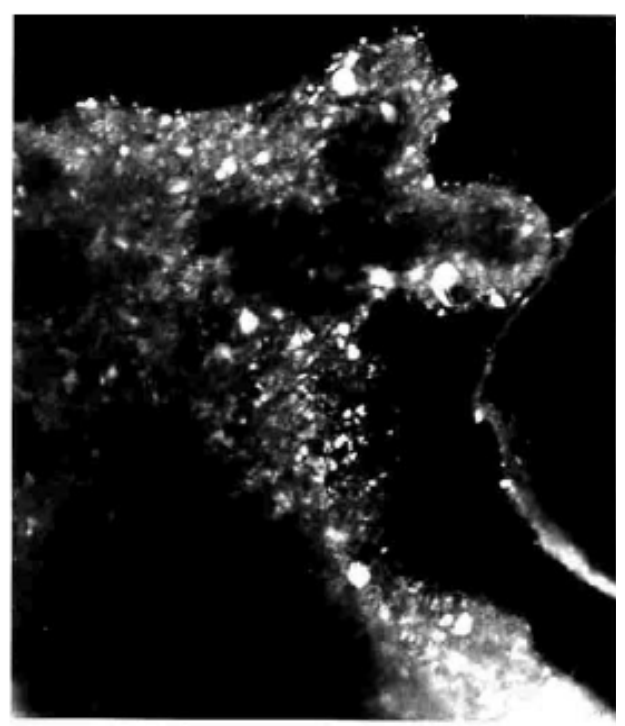

(b)

Fig. 22. $\mathrm{Cr}_{3} \mathrm{C}_{2}-\mathrm{NiCr}$ powder milled for $20 \mathrm{~h}$ : (a) Bright field image; and (b) dark field image. White particles are $\mathrm{Cr}_{3} \mathrm{C}_{2}$, and dark matrix is $\mathrm{NiCr}$ (He et al; 2002). 


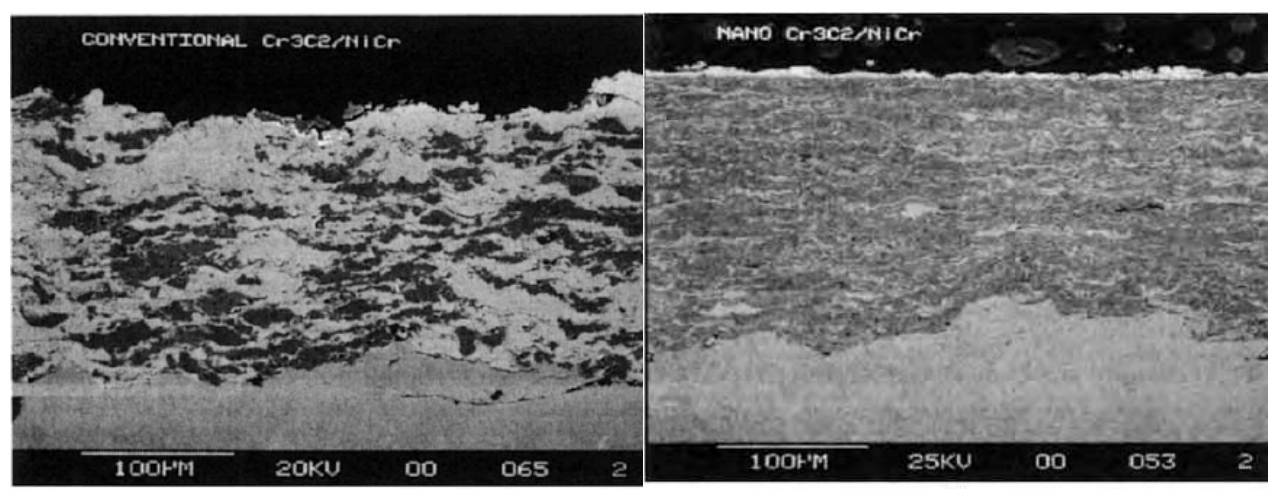

(a)

(b)

Fig. 23. Microstructure of $\mathrm{Cr}_{3} \mathrm{C}_{2}-25$ (Ni20Cr): (a) conventional coating; (b) nanostructure coating (He et al; 2002).

\subsection{Amorphous-nanocrystalline materials}

Amorphous metallic alloys have been of interest not only for fundamental studies, but also for potential applications for over 40 years. Amorphous structures have been made in many alloy systems and show a variety of unique properties compared to their crystalline counterparts. These properties are associated with the amorphous atomic structure and include high yield strength, large elastic limit, high corrosion resistance, good wear resistance, and low elastic modulus (Greer et al; 2002; Schuh et al; 2007). Amorphization by high energy mechanical alloying of elemental powders occurs by an inter-diffusion reaction at relatively low temperature along constituent interfaces. The formation of amorphous phase by MA process depends on the energy provided by the milling machine and thermodynamic properties of the alloy system. The thermodynamic and kinetic principles for amorphization through solid state synthesis or mechanical alloying are discussed by Schwarz and Johnson (Schwarz \& Johnson, 1883). They identified two rules for the formation of amorphous alloy by MA in an A-B binary system: (1) A large negative heat of mixing, $\Delta \mathrm{H}_{\text {mix }}$, between the elemental constituents. (2) A large asymmetry in the diffusion coefficients of the constituents. An amorphous phase is kinetically obtained only if the amorphization reaction is much faster than that for the crystalline phases. It is also believed that during mechanical milling of a homogeneous crystalline alloy, the internal energy of lattice increases due to the introduction of crystal defects. When the free energy of the crystalline structure exceeds the free energy of the amorphous phases, crystalline structure can transform to an amorphous phase (Suryanarayana, 2001, 2004).

Fe-based amorphous alloys and thermal spray coatings are perhaps the most important system for possible applications because of the low cost of iron, and the relatively high strength and hardness of Fe-based amorphous alloys (Chen et al; 2006; Sunol et al; 2001). Extensive research has been carried out on the mechanical alloying of Fe-based amorphous alloys including binary $\mathrm{Fe}-\mathrm{B}, \mathrm{Fe}-\mathrm{Cr}$, and $\mathrm{Fe}-\mathrm{Zr}$ (Schuh et al; 2007), ternary $\mathrm{Fe}-\mathrm{Zr}-\mathrm{B}$ (Suryanarayana, 2001, 2004) and Fe-Si-B (Chen et al; 2006 ) and multi-component Fe-Ni$\mathrm{Si}(\mathrm{P})-\mathrm{B}$ (Chen et al; 2005 ), Fe-Al-P-C-B (Minic et al; 2009) and $\mathrm{Fe}-\mathrm{Nb}-\mathrm{Cu}-\mathrm{Si}-\mathrm{B}$ (Inoue et al; 2000) alloys. Movahedi et al, reported the MA amorphization of $70 \mathrm{Fe}-15 \mathrm{Cr}-4 \mathrm{Mo}-5 \mathrm{P}-1 \mathrm{C}-$ 
1Si-4B (wt.\%) elemental powder which includes four types of elements: late transition metal $(\mathrm{Fe})$, early transition metals $(\mathrm{Cr}, \mathrm{Mo})$, metalloids $(\mathrm{B}, \mathrm{P}, \mathrm{Si})$, and graphite. The atomic sizes of these elements are in the order of $\mathrm{Mo}(0.139 \mathrm{~nm})>\mathrm{Si}(0.132 \mathrm{~nm})>\mathrm{P}(0.128 \mathrm{~nm})>\mathrm{Cr}(0.127$ $\mathrm{nm})>\mathrm{Fe}(0.126 \mathrm{~nm})>\mathrm{B}(0.098 \mathrm{~nm})>\mathrm{C}(0.091 \mathrm{~nm})$. This composition yields new atomic pairs of $\mathrm{Fe}-(\mathrm{Cr}, \mathrm{Mo}),(\mathrm{Cr}, \mathrm{Mo})-(\mathrm{B}, \mathrm{P}, \mathrm{Si})$ and $\mathrm{Fe}-(\mathrm{B}, \mathrm{P}, \mathrm{Si})$ with various negative heats of mixing. These properties suggest that $\mathrm{Fe}-\mathrm{Cr}-\mathrm{Mo}-\mathrm{B}-\mathrm{P}-\mathrm{C}-\mathrm{Si}$ composition has a high glass forming ability (GFA) and appropriate thermal stability (Movahedi et al; 2010a \& b).

Fig. 24. shows the XRD patterns of powder mixture as a function of high energy milling (i.e., Retch PM100) times. As-received powder mixture shows sharp crystalline peaks of elemental Fe, Cr, Mo, B, C and Si. Red phosphorus is absent on XRD pattern because of its amorphous nature. As milling progresses, the XRD peaks of the elemental constituents are broadened with a corresponding decrease in their intensities. These effects are caused by a continuous decrease effective crystallite size and an increase of the atomic level strain, as a result of the induced-plastic deformation during MA (Filho et al; 2000; Zhang, 4004). After $15 \mathrm{~h}$ of milling time, the $\mathrm{Cr}, \mathrm{Mo}, \mathrm{Si}, \mathrm{B}$ and $\mathrm{C}$ peaks vanished. This may be due to the dissolution of these elements into Fe matrix and/or to their ultra fine crystallite size. There is no significant reaction between the elemental powders at this stage of milling as no new phase was detected. On continued milling a broad peak was developed on the XRD pattern, owing to the formation of an amorphous phase. Meanwhile the crystalline peaks of Fe remain distinct. This structure transforms to an amorphous phase on further milling till $80 \mathrm{~h}$ of milling time (Movahedi et al; 2010a).

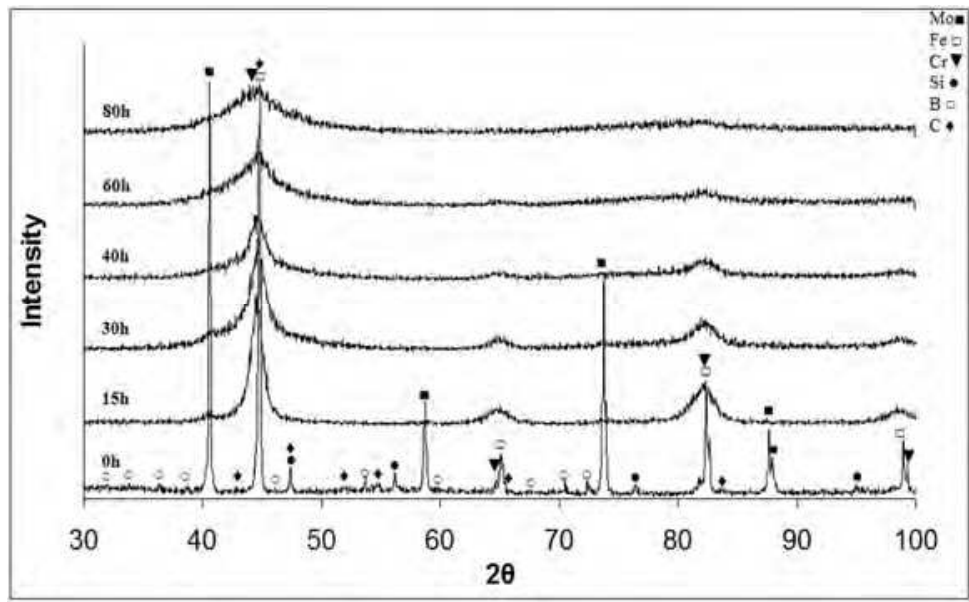

Fig. 24. XRD patterns of 70Fe-15Cr-4Mo-5P-1C-1Si-4B powders as-received and after different milling times (Movahedi et al; 2010a).

Movahedi et al. suggested that the transformation of supersaturated solid solution of Fe to amorphous structure during milling is believed to occur as a result of the internal energy increase of the crystalline structure due to the creation of a high density of lattice defects as well as the dissolution of a great amount of solute atoms with different sizes in Fe lattice. When the free energy of the crystalline solid solution exceeds the free energy of the amorphous state, the crystalline structure thermodynamically becomes unstable and 
transform to the amorphous structure. This behavior can be accounted for by considering the interaction parameters, proposed by Inoue et al. (Inoue et al; 2000) which describe the difference in bonding energy between the atomic pairs $\mathrm{Fe}-\mathrm{P}-\mathrm{C}$ and $\mathrm{Fe}-\mathrm{B}-\mathrm{C}$ in the ternary $\mathrm{Fe}-\mathrm{A}-\mathrm{C}$ system. The effect of $\mathrm{B}$ addition is presumably to generate attractive bonding among the constituent elements. In the $\mathrm{Fe}-\mathrm{A}-\mathrm{C}$ system with a negative interaction parameter, the enthalpy of mixing is also negative. In such a case, the formation of the FeA-C solution decreases the free energy of the system by lowering the system mixing enthalpy. These interaction parameters characterize the effect of a third element on amorphization reaction of Fe-C binary alloys processed by mechanical alloying (Inoue et al; 2000; Olofinjana et al; 2007; Suryanarayana, 2001).

Fig. 25. shows cross-sectional SEM images of the powder particles after 2, 4, 10, 15, 30 and $80 \mathrm{~h}$ of milling. During the early stage of milling, the powder particles are flattened by compressive forces due to the collision of the balls. Thus, micro-forging action deforms the powder particles plastically leading to work hardening and fracturing. The creation of new surfaces enable the particle to weld together and thus to produce a typical lamellar structure consisting of pure elements (Movahedi et al; 2009). On continued ball milling, the layered structure is progressively refined (Fig. 25d-f). At longer milling times the structure became featureless on SEM as a result of development of Fe-base solid solution and subsequent amorphous phase.
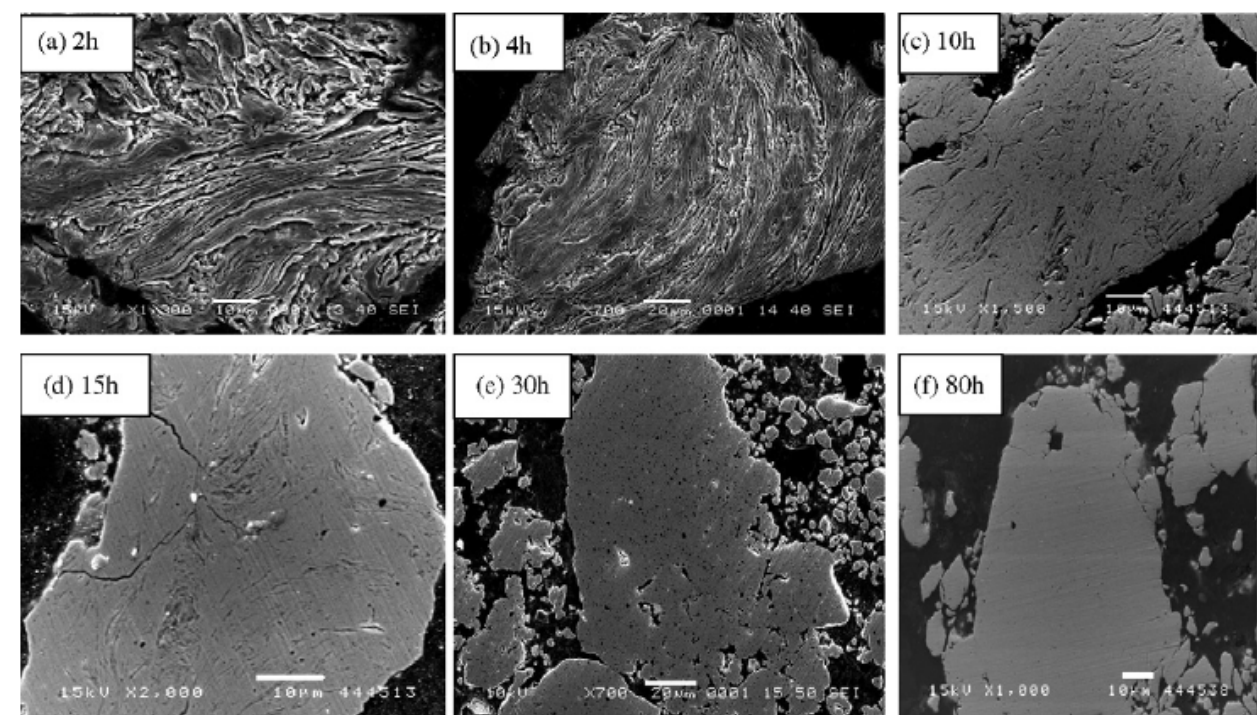

Fig. 25. cross-sectional SEM images of 70Fe-15Cr-4Mo-5P-1C-1Si-4B powders after different milling times (Movahedi et al; 2010a).

High resolution transition electron microscopy (HRTEM) and selected-area diffraction pattern (SADP) of powders milled for $15 \mathrm{~h}$ confirmed the formation of a nanocrystalline structures (Fig. 26a). After $40 \mathrm{~h}$ of milling time amorphous and nanocrystalline phases coexisted in the milled powders. Fig. 26b shows that most amorphous phase is developed at the edge of powder particles indicating that the amorphization reaction starts at edge of 
particles and progress into the internal regions as MA proceeds. The SADP in Fig. 26b shows some diffraction spots within the amorphous diffuse ring. Furthermore the fast Fourier transform (FFT) images showed a broad diffuse ring at the edge and crystalline diffraction spots at the center of particles (arrows in Fig. 26b) suggesting that the sample contains both amorphous and nanocrystalline phases. Fig. 26c is the HRTEM image and SADP of mechanically alloyed powder after $80 \mathrm{~h}$ of milling time, showing a fully amorphous microstructure (Movahedi et al; 2010a, 2011).
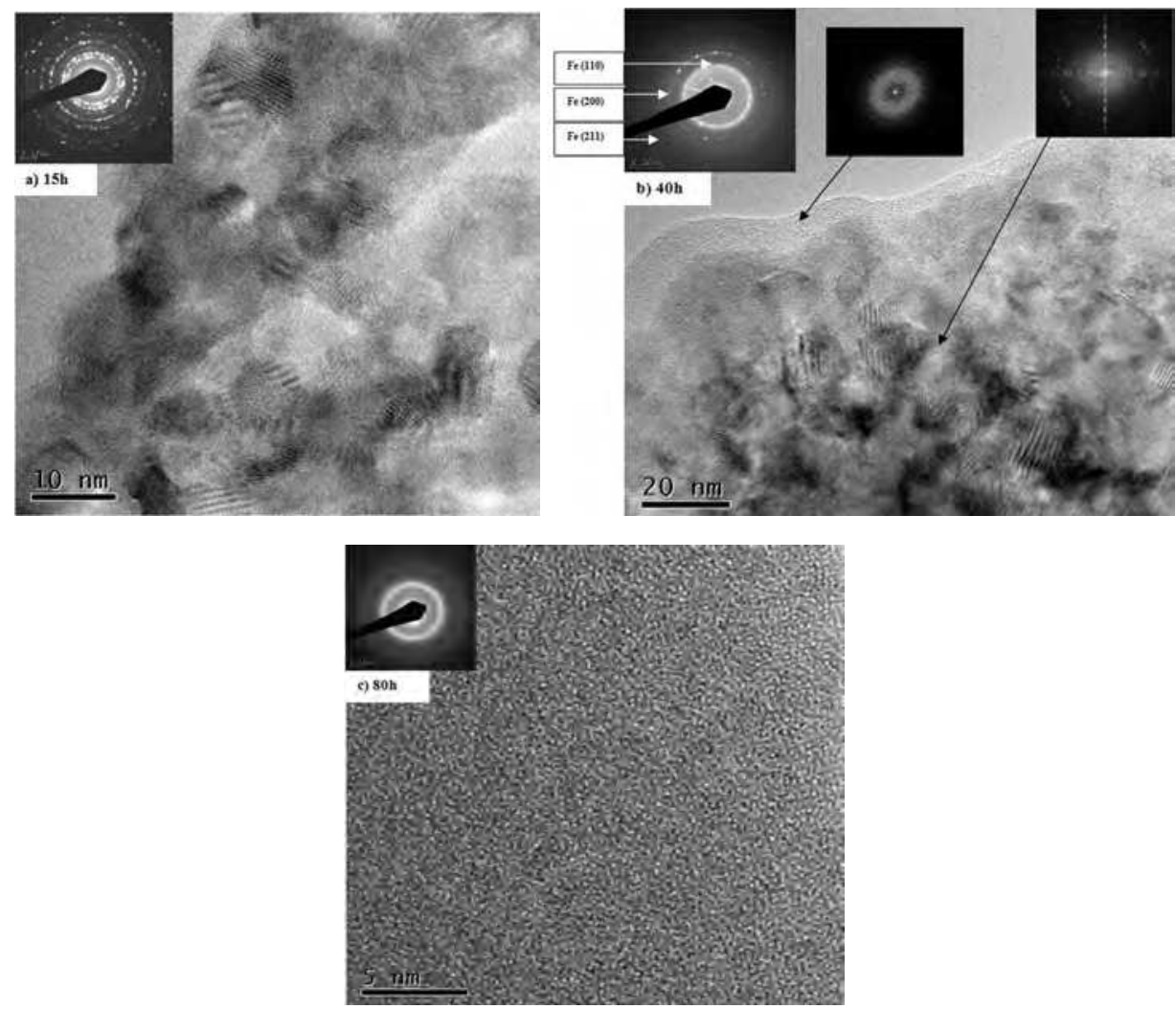

Fig. 26. HRTEM micrographs, SADP and FFT patterns of $70 \mathrm{Fe}-15 \mathrm{Cr}-4 \mathrm{Mo}-5 \mathrm{P}-1 \mathrm{C}-1 \mathrm{Si}-4 \mathrm{~B}$ amorphous powder after different milling times (Movahedi et al; 2010a, 2011).

Synthesizing amorphous and/or nanocrystalline layers on metal substrates can be utilized to improve surface performance such as wear and corrosion resistance (Kim et al; 2007). Greer et al. reported that amorphous alloys can have very good resistance to sliding and abrasive wear and the coatings can have low friction coefficient (Greer et al; 2002). Thermal spraying process is one of the techniques to deposit amorphous coatings on surfaces, where the amorphous structure is retained due to the sufficiently rapid cooling that inhibits longrange diffusion and crystallization. On impact with the substrate, droplet spreading occurs to give lamellar morphologies with cooling rates of $10^{7}-10^{8} \mathrm{~K} / \mathrm{s}$ (Wu et al; 2006). A number of researchers have investigated the use of air plasma spraying (APS), low pressure plasma 
spraying (LPPS) and vacuum plasma spraying (VPS) to deposit alloys, which are capable of solidifying as metallic glasses. Kishitake et al. reported that mixed amorphous and crystalline structures are obtained in APS and LPPS coatings (Kishitake et al; 1996). In recent years, there has been an increasing interest in the use of HVOF for depositing protective coatings. The general methodology involves designing alloys that have low critical cooling rates for glass formation. Alloys with high glass forming ability (GFA) would be favorable for forming fully amorphous phase coating by HVOF process.

The amorphous coatings, while exhibiting interesting properties, can be heated up above their crystallization temperature to initiate devitrification and yield amorphousnanocrystalline mixture. Since the driving force for the crystallization is extremely high and the diffusion rate in the solid state, at the crystallization temperature, is very low, an extremely high nucleation frequency results. There is limited time for growth before impingement between neighbouring crystallites occurs, resulting in the formation of nanoscale microstructures. Some researchers (Branagan et al; 2001; Kishitake et al; 1996; Otsubo et al; 2000), mentioned that the formation of Fe-base amorphous coatings by LPPS, high-energy plasma spraying (HPS), and HVOF processes with using atomized feedstock powder. In recent years, as mentioned earlier, Movahedi, et al. first synthesised the amorphous mechanical alloying feedstock powder in a new composition 70Fe-15Cr-4Mo-5P4B-1C-1Si (wt.\%) with high GFA and then developed them to amorphous-nanocrystalline coatings with HVOF and plasma spray process (Movahedi, 2010c, 2011).

Fig. 27. illustrates the XRD patterns of mechanically alloyed Fe-Cr-Mo-P-B-C-Si feedstock powder and the as-sprayed HVOF coatings. The presence of halo on XRD pattern confirms that the feedstock MA powder used for HVOF spraying has an amorphous structure. The XRD pattern of HVOF-G1 coating also shows a halo characteristic indicating that this coating has an amorphous structure similar to feedstock MA powder. However, in HVOFG2 there is an emergent crystalline peak on the top of the amorphous hub suggesting that this coating is a mixture of amorphous and crystalline phases. Structure of HVOF-G3 coating mainly consists of crystalline phases such as a-Fe, $\mathrm{Fe}_{23}(\mathrm{C}, \mathrm{B})_{6}$, and $\mathrm{Fe}_{5} \mathrm{C}_{2}$.

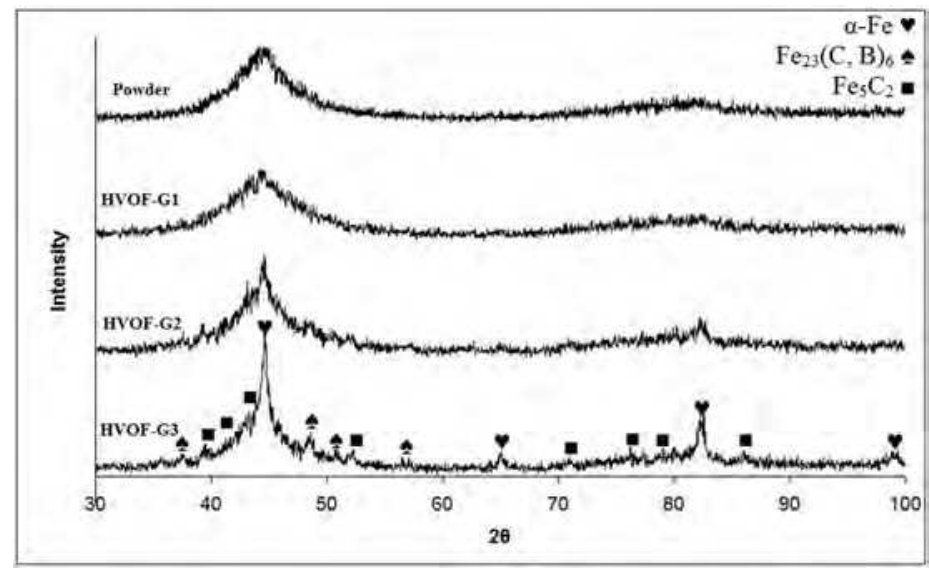

Fig. 27. XRD patterns of mechanically alloyed feedstock powder and Fe-Cr-Mo-P-B-C-Si HVOF coatings (Movahedi et al; 2010c, 2011). 
Movahedi, et al. inferred from the diffraction patterns that a full range of amorphous to fully crystalline microstructures can be obtained by adjusting of HVOF parameters especially fuel/oxygen ratio (Table 2). They suggested that the difference in the glassy fraction is related to the mechanism of the amount of cooling rate and remelting of individual particles in HVOF flame at various fuel/oxygen ratios. By increasing fuel/oxygen ratio, the flame temperature becomes too high and the velocity of the powder particles is much higher. Thus, the powder particles were completely remelted in the HVOF flame and then were rapidly solidified and quenched on the cold substrate forming an amorphous structure. By decreasing the fuel/oxygen ratio the particles did not remelt to a significant extent as well as the velocity of them becomes lower, thus the conditions appear to crystallize the amorphous feedstock powder in flame which explains the higher percentage of crystalline phase in the HVOF-G3 (Movahedi, 2010c, 2011; Shin et al; 2007).

Kishitake et al. reported that for Fe-17Cr-38Mo-4C gas atomized powder, amorphous coatings are obtained by the APS while a mixture of amorphous and crystalline phases are formed by HVOF (Kishitake et al; 1996). They suggested that this difference may result from the difference of the cooling rate between the APS and HVOF processes. It is regarded that the composition chosen by Movahedi, et al. satisfies the three empirical rules (Pang et al; 2002) for the stabilization of the super-cooled liquid during HVOF and plasma spraying, leading to highly dense random packed atomic configurations, higher viscosity, and lower atomic diffusivity (Kobayashi et al; 2008) which is primarily attributed to the high GFA.

\begin{tabular}{lccc}
\hline & \multicolumn{3}{c}{ Microstructure } \\
\cline { 2 - 4 } Parameters & $\begin{array}{c}\text { Amorphous } \\
\text { (HVOF-G1) }\end{array}$ & $\begin{array}{c}\text { Amorphous- } \\
\text { Nanocrystalline } \\
\text { (HVOF-G2) }\end{array}$ & $\begin{array}{c}\text { Nanocrystalline } \\
\text { (HVOF-G3) }\end{array}$ \\
\hline Oxygen gas flow rate (SLPM) & 833 & 682 & 560 \\
Fuel (Kerosene) flow rate (SLPM) & 0.37 & 0.21 & 0.14 \\
Fuel/Oxygen (Vol\%) & 0.044 & 0.031 & 0.025 \\
Powder feed rate (g/min) & 35 & 35 & 35 \\
Spray distance (mm) & 300 & 300 & 300 \\
Scanning Velocity (mm/s) & 50 & 50 & 50 \\
Deposit thickness $(\mu \mathrm{mm})$ & 300 & 300 & 300 \\
Nozzle length (mm) & 100 & 100 & 100 \\
Compress air cooling & yes & yes & yes \\
\hline
\end{tabular}

Table 2. HVOF spraying parameters for advanced structures (Movahedi et al; 2010c, 2011).

Typical SEM cross section image of HVOF coatings is shown in Fig. 28. As it can be seen, the microstructure of coatings includes very fine lamella structure which is smooth and dense, adhering well with the substrate with no cracking. Moreover, some pores are rarely observed in this microstructure as indicated by arrows can be seen from the images. The big pores located between flattened droplets are mainly caused by the loose packed layer structure or gas porosity phenomenon, while the small pores within the flattened particles originate from the shrinkage porosity (Totemeier, 2005). Obviously, the porosity of the coatings reduces in the order of HVOF-G3, G2, and G1, and it is believed that increasing the fuel/oxygen ratio, increases both the thermal and kinetic energy of the gas flow, so that the majority of the powder particles are better melted and also accelerated to higher velocities 
and deformed extensively on impact to form elongated lamella (Ji, 2005). Some unmelted particles are clearly visible in HVOF-G3 (Fig. 28c) coating because of lower flame temperature (minimum fuel/oxygen ratio).
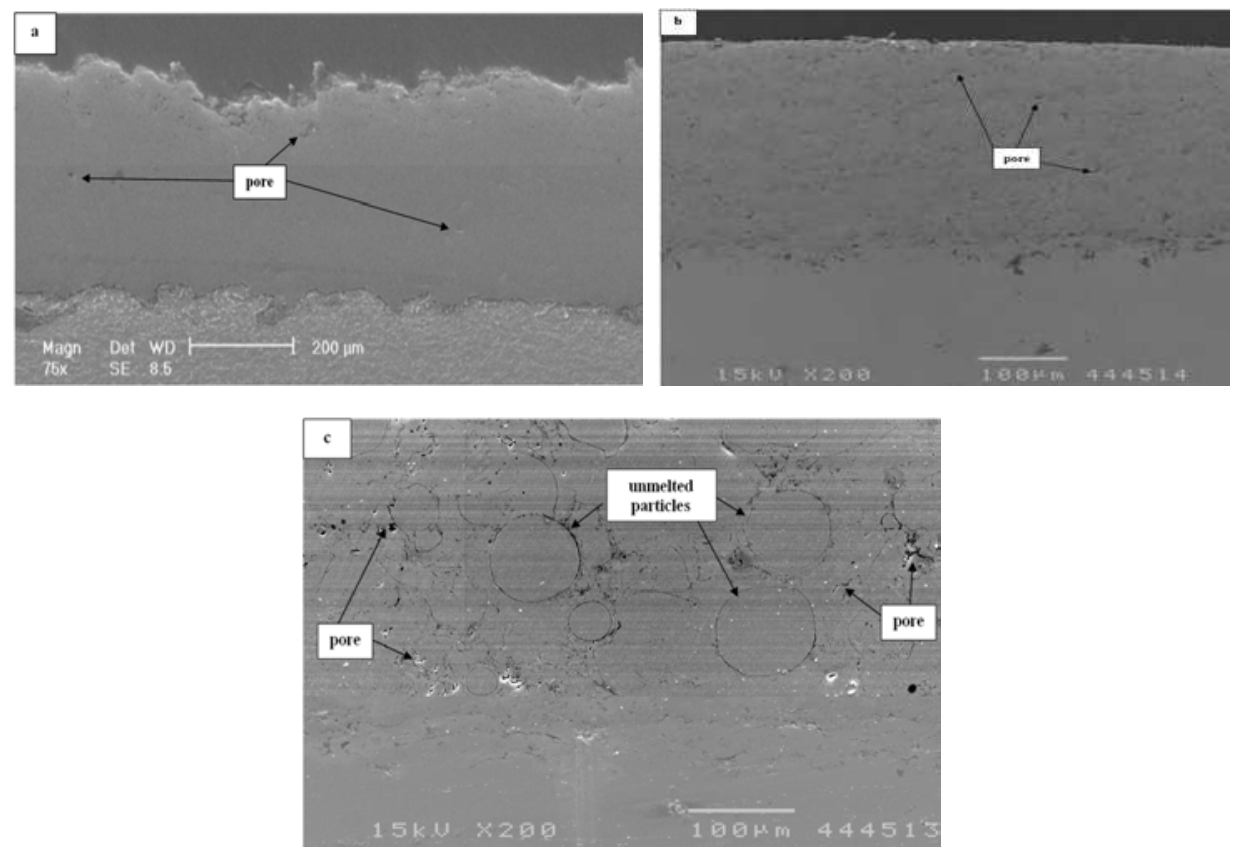

Fig. 28. SEM cross-sectional images of Fe-Cr-Mo-P-B-C-Si coatings (a) HVOF-G1, (b) HVOFG2, and (c) HVOF-G3 (Movahedi et al; 2010c).

HRTEM image has shown in Fig. 29. confirms that HVOF-G1 coating is completely amorphous. As it can be seen in Table 2, this microstructure appears when the fuel/oxygen ratio has a maximum value. As shown in Fig. 30. the HVOF-G2 coating consists of amorphous phase and nanocrystalline grains. The electron diffraction pattern, in Fig. 30(a) was taken with the selected area aperture centered over the amorphous and nanocrystalline region and shows a diffuse amorphous halo with diffraction spots arising from nanocrystalline grains with a size range of 5-30 $\mathrm{nm}$. The HRTEM micrograph and fast Fourier transform (FFT), as shown in Fig. 30(b), confirm the presence of a mixture of nanocrystalline grains within an amorphous matrix. In this case the fuel/oxygen ratio is moderate (HVOF-G2) so this duplex microstructure can be explained by quenching of semimolten particles when impinged to the cold substrate. Therefore, some unmelted particles crystallized inside the HVOF flame to yield nanocrystalline grains which embedded within the amorphous matrix. A nanocrystalline structure with equiaxed nanograins was obtained in case of HVOF-G3 coating (Fig. 30c). In this condition the fuel/oxygen ratio has a minimum value and the HVOF flame temperature is the lowest so the most of the individual powder particles were unmelted and crystallized inside the HVOF flame. Moreover, the cooling rate was sufficiently high to avoid grain coarsening and yielded nanocrystalline structure (Movahedi et al; 2010c, 2011). 


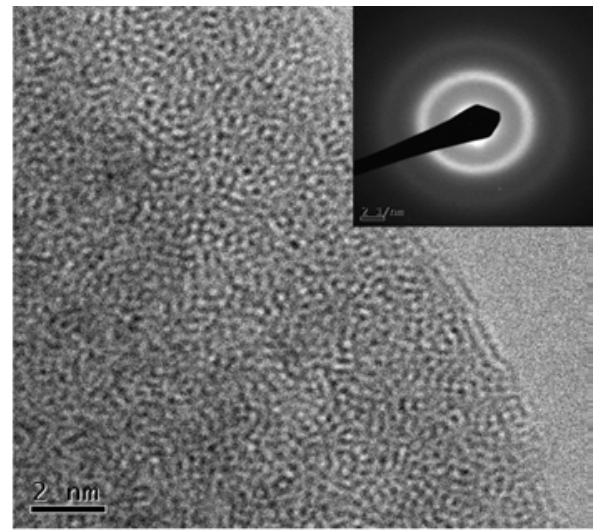

Fig. 29. HRTEM micrograph and SADP of amorphous Fe-Cr-Mo-P-B-C-Si HVOF coating (HVOF-G1) (Movahedi et al; 2010c, 2011).
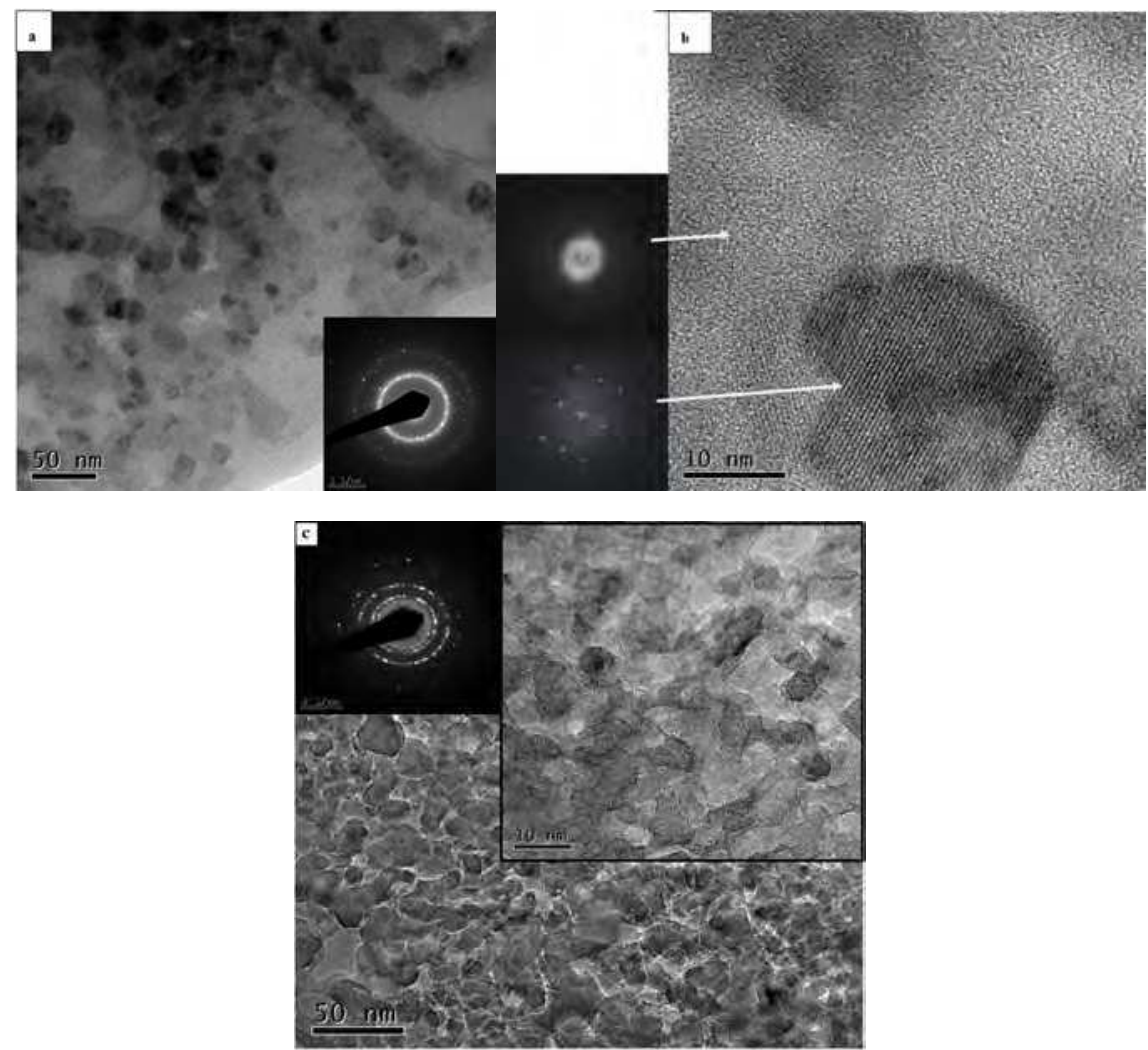

Fig. 30. (a) TEM and (b) HRTEM micrographs, SADP and FFT of amorphous-nanocrystalline Fe-Cr-Mo-P-B-C-Si HVOF coatings (HVOF-G2), and (c) TEM, HRTEM micrographs and SADP of nanocrystalline of HVOF-G3 (Movahedi et al; 2010c, 2011). 
Movahedi, et al. reported that the microhardness value of HVOF coatings are all have a high hardness of around 800 to $1200 \mathrm{HV}$. The value of hardness was similar to that of the bulk Febased metallic glass (Kobayashi et al; 2008) but it was higher than that of electroplated chromium and the Ni-based amorphous coatings (Ni et al; 2009). The difference in hardness value of the three groups of HVOF coatings were developed by Movahedi, et al. is attributed mainly to the difference in volume fraction of amorphous and nanocrystalline phases. A fully amorphous coating has lower hardness $(830 \mathrm{HV})$ compared to the duplex amorphous-nanocrystalline coating $(950 \mathrm{HV})$. The fully nanocrystalline coating has the highest microhardness $(1230 \mathrm{HV})$, probably due to precipitation of some carbides such as $\mathrm{Fe}_{23}(\mathrm{C}, \mathrm{B})_{6}$ and $\mathrm{Fe}_{5} \mathrm{C}_{2}$ during crystallization (Movahedi, 2010c). Some researchers suggested that the hardness of the amorphous Fe-base coating increases after crystallization (Branagan et al; 2005). In contrast Kishitake et al. reported that the duplex microstructure consisting of the both amorphous and nanocrystalline structure exhibits a higher hardness than fully amorphous or nanocrystalline structure (Kishitake et al; 1996). The difference is mainly attributable to the difference of decomposition of amorphous phase during crystallization.

\section{Conclusion}

This chapter reviews the solid state synthesis and characterization of advanced feedstock powders used in various thermal spray techniques, and processing and characterization of amorphous-nanostructured related coatings. The published results show that mechanical milling can be effectively used to synthesize advanced materials and nanocomposite powders. On the other hand, whether a composite or a single-phase starting powder is involved, mechanical milling leads to the formation of nanocrystalline structure under certain milling conditions.

\section{References}

Atzmon, M. (1990). In Situ Thermal Observation of Explosive Compound-Formation Reaction During Mechanical Alloying, Physical Review Letter, 64, pp. 487-490

Berndt, C.C. (1992). Materials Production for Thermal Spray Processes, Education Module on Thermal Spray, Pub. ASM International, OH, Materials Park, USA

Boldyrev, V.V. \& Tkacova, K. (2000). Mechanochemistry of Solids: Past, Present and Prospects, Journal of Materials Synthesis and Processing, 8, pp. 121-132

Branagan, D.J; Swank, W.D; Haggard, D.C. \& Fincke, J.R. (2001). Wear-Resistant Amorphous and Nanocomposite Steel Coatings, Metallurgical and Materials Transcation A, 32, pp. 2615-2621

Branagan, D.J; Breitsameter, M; Meacham, B.E. \& Belashchenko, V. (2005). HighPerformance Nanoscale Composite Coatings for Boiler Applications, Journal of Thermal Spray Technology, 14, 2, pp. 196-204

Chen, T; Hampikian, J.M. \& Thadhani, N.N. (1999). Synthesis and Characterization of Mechanically Alloyed and Shock-Consolidated Nanocrystalline NiAl Intermetallic, Acta Materialia, 47, 8, pp. 2567-2579.

Chen, Q.J; Fan, H.B; Shen, J; Sun, J.F. \& Lu, Z.P. (2006). Critical Cooling Rate and Thermal Stability of Fe-Co-Zr-Y-Cr-Mo-B Amorphous Alloy, Journal of Alloys and Compounds, 407, pp. 125-128 
Chen, Q.J; Fan, H.B; Ye, L; Ringer, S; Sun, J.F; Shen, J. \& McCartney, D.G. (2005). Enhanced Glass Forming Ability of Fe-Co-Zr-Mo-W-B Alloys with Ni Addition, Materials Science and Engineering A, 402, pp. 188-192

Chung, C.Y; Zhu, M. \& Man, C.H. (2002). Effect of Mechanical Alloying on the Solid State Reaction Processing of Ni-36.5 at.\%Al Alloy, Intermetallics, 10, pp. 865-871

Deevi, S.C; Sikka, V.K; Swindeman, C.J. \& Seals, R.D. (1997). Reactive Spraying of NickelAluminide Coatings, Journal of Thermal Spray Technology, 6, pp. 335-344

Eigen, N; Klassen, T. \& Aust, E. (2003). Production of Nanocrystalline Cermet Thermal Spray Powders for Wear Resistant Coatings by High-Energy Milling, Materials Science and Engineering A, 356, pp. 114-121.

Eigen, N; Gartner, F; Klassen, T; Aust, E; Bormann, R. \& Kreye, H. (2005). Microstructures and Properties of Nanostructured Thermal Sprayed Coatings Using High-Energy Milled Cermet Powders, Surface and Coatings Technology, 195, pp. 344- 357

El-Eskandarany, M.S. (2001). Mechanical Alloying for Fabrication of Advanced Engineering Materials, Noyes Publications, 0-8155-1462-X, New York

Enayati, M.H; Karimzadeh, F; Tavoosi, M; Movahedi, B. \& Tahvilian, A. (2011). Microstructural Characterization of Nanostructured NiAl Coatings Prepared by Mechanical Alloying and HVOF Technique, Journal of Thermal Spray Technology, 20, 5, pp. 440-446

Enayati, M.H; Sadeghian, Z; Salehi, M. \& Saidi, A. (2004). The Effect of Milling Parameters on the Synthesis of $\mathrm{Ni}_{3} \mathrm{Al}$ Intermetallic Compound by Mechanical Alloying, Materials Science and Engineering A, 375-377, pp. 809-811

Enayati, M.H; Karimzadeh, F. \& Anvari, S.Z. (2008). Synthesis of Nanocrystalline NiAl by Mechanical Alloying, Journal of Materials Processing and Technology, 200, pp. 312-315

Filho, A.F; Bolfarini, C; Xu, Y. \& Kiminami, C.S. (2000). Amorphous Phase Formation in Fe6.0wt\%Si Alloy by Mechanical Alloying, Scripta Materialia, 42, pp. 213-217

Greer, A.L; Rutherford, K.L. \& Hutchings, I.M. (2002). Wear Resistance of Amorphous Alloys and Related materials, International Materials Review, 47, pp. 87-112

Goldenstein, H; Silva, Y.N. \& Yoshimura, H.N. (2004). Designing a New Family of High Temperature Wear Resistant Alloys Based on Ni 3 Al-IC: Experimental Results and Thermodynamic Modeling, Intermetallics, 12, pp. 963-968

He, J; Ice, M. \& Lavernia, E.J. (1998). Synthesis and characterization of nanostructured $\mathrm{Cr}_{3} \mathrm{C}_{2-}$ $\mathrm{NiCr}$, Nanostructured Materials, 10, pp. 1271-1283

Hearley, J.A; Little, J.A. \& Sturgeon, A.J. (2000). The Effect of Spray Parameters on the Properties of High Velocity Oxy-Fuel NiAl Intermetallic Coatings, Surface and Coating Technology, 123, pp. 210-218

Hearley, J.A; Little, J.A. \& Sturgeon, A.J. (1999). The Erosion Behaviour of NiAl Intermetallic Coatings Produced by High Velocity Oxy-Fuel Thermal Spraying, Wear, 233, pp. 328-333

He, J. \& Schoenung, J.M. (2002). Nanostructured Coatings, Materials Science and Engineering A, 336, 274-319.

Horlock, A.J; Sadeghian, Z; McCartney, D.G. \& Shipway, P.H. (2005). High-Velocity Oxyfuel Reactive Spraying of Mechanically Alloyed Ni-Ti-C Powders, Journal of Thermal Spray Technology, 14, 1, pp. 77-84 
Houben, J.M. \& Zaat, J.H. (1973). Investigations into the Mechanism of Exothermically Reacting Nickel-Aluminum Spraying Materials, Proceedings of Seventh International Metal Spray Conference, pp. 77-88, London, Welding Institute, Sept 1973

Inoue, M; Suganuma, K. \& Nihara, K. (2000). Fracture Mechanism of $\mathrm{Ni}_{3} \mathrm{Al}$ Alloys and their Composites with Ceramic Particle at Elevated Temperatures, Intermetallics, 8, pp. 365-370

Inoue, A. \& Wang, X.M. (2000). Bulk Amorphous Fc20(Fe-C-Si) Alloys with Small Amounts of B and Their Crystallized Structure and Mechanical Properties, Acta Materialia, 48, pp. 1383-1395

Ji, G; Elkedim, O. \& Grosdidier, T. (2005). Deposition and Corrosion Resistance of HVOF Sprayed Nanocrystalline Iron Aluminide Coatings, Surface and Coating Technology, 190, pp. 406-416

Kim, Y.S; Kim, K.T; Kim, B.T. \& Bae, J.I. (2007). Microstructure and Wear Behavior of Thermally Sprayed Fe-based Amorphous Coating, Key Engineering Materials, 353358, pp. 848-851

Kishitake, K; Era, H. \& Otsubo, F. (1996). Thermal-Sprayed Fe-10Cr-13P-7C Amorphous Coatings Possessing Excellent Corrosion Resistance, Journal of Thermal Spray Technology, 5, 4, pp. 476-482

Koch, C.C. (1997). Synthesis of Nanostructured Materials by Mechanical Milling: Problems and Opportunities, Nanostructured Materials, 9, pp. 13-22

Kobayashi, A; Yano, S; Kimura, H. \& Inoue, A. (2008). Mechanical Property of Fe-base Metallic Glass Coating formed by Gas Tunnel Type Plasma Spraying, Surface and Coating Technology, 202, pp. 2513-2518

Knotek, O; Lugscheider, E. \& Eschnauer, H.R. (1973). Reactive Kinetic Observations for Spraying with Ni-Al Powder, Proceedings of Seventh International Metal Spray Conference, pp. 72-76, London, Welding Institute, Sept 1973

Lee, D.B. \& Kim, D. (2001). The Oxidation of $\mathrm{Ni}_{3} \mathrm{Al}$ Containing Decomposed SiC Particles, Intermetallics, 9, pp. 51-56

Maric, R; Ishihara, K.N. \& Shingu, P.H. (1996). Structural changes during low energy ball milling in the Al-Ni system, Journal of Materials Science Letter, 15, pp. 1180-1183

Mashreghi, A. \& Moshksar, M.M. (2009). Partial Martensitic Transformation of Nanocrystalline NiAl Intermetallic During Mechanical Alloying, Journal of Alloys and Compounds, 482, pp. 196-198

Minic, D.M; Maricic, A. \& Adnadevic, B. (2009). Crystallization of a-Fe Phase in Amorphous Fe81B13Si4C2 Alloy, Journal of Alloys and Compounds, 473, pp. 363-367

Morris, D.G. (1998). Possibilities for High-Temperature Strengthening in Iron Aluminides, Intermetallic, 6, pp. 753-758

Morsi, K. (2001). Reaction Synthesis Processing of Ni-Al Intermetallic Materials, Materials Science and Engineering A, 299, pp. 1-15

Movahedi, B; Enayati, M.H. \& Salehi, M. (2009). Thermal Spray Coatings of Ni-10wt.\%Al Composite Powder Synthesis by Low Energy Mechanical Milling, Surface Engineering, 25, 4, pp. 276-283

Movahedi, B; Enayati, M.H. \& Salehi, M. (2005). Synthesis of Ni-Al Composite Coating in Thermal Spray Applications by Utilizing Low Energy Ball Milling Powder, Proceeding of Ninth Iranian Metallurgical Engineering Society Conference, Shiraz University, Shiraz, Oct. 2005a 
Movahedi, B; Enayati, M.H. \& Salehi, M. (2005). Investigation of Adhesion Strength Thermal Spray Coating of Mechanical Alloying Ni-Al Powders, Proceeding of Eighth Heat Treatment and Surface Engineering National Conference, Isfahan University of Technology, Isfahan, May. 2005b

Movahedi, B; Enayati, M.H. \& Wong, C.C. (2010). Study on Nanocrystallisation and Amorphisation in Fe-Cr-Mo-B-P-Si-C System during Mechanical Alloying, Journal of Materials Science and Engineering B, 172, pp. 50-54 a

Movahedi, B; Enayati, M.H. \& Wong, C.C. (2010). On the Crystallization Behavior of Amorphous Fe-Cr-Mo-B-P-Si-C Powder Prepared by Mechanical Alloying, Materials letter, 24, 9, pp. 1055-1058 b

Movahedi, B; Enayati, M.H. \& Wong, C.C. (2010). Structural and Thermal Behavior of Fe-CrMo-P-B-C-Si Amorphous and Nanocrystalline HVOF Coatings, Journal of Thermal Spray Technology, 19, 5, pp. 1093-1099 c

Movahedi, B. \& Enayati, M.H. (2011). Fe-Based Amorphous-Nanocrystalline Thermal Spray Coatings, 2011 TMS Annual Meeting and Exhibition, pp. 17-24, San Diego, 27 Feb3Mar 2011

Ni, H.S; Liu, X.H; Chang, X.C; Hou, W.L; Liu, W. \& Wang, J.Q. (2009). High Performance Amorphous Steel Coating Prepared by HVOF Thermal Spraying, Journal of Alloys and Compounds, 467, pp. 163-167

Olofinjana, A.O. \& Tan, K.S. (2007). Thermal Devitrification and Formation of Single Phase Nano-Crystalline Structure in Fe-Based Metallic Glass Alloys, Journal of Materials Processing and Technology, 191, pp. 377-380

Otsubo, F; Era, H. \& Kishitake, K. (2000). Formation of Amorphous Fe-Cr-Mo-8P-2C Coatings by the High Velocity Oxy-Fuel Process, Journal of Thermal Spray Technology, 9, 4, pp. 494-498

Pawlowski, L. (2008). The Science and Engineering of Thermal Spray Coatings, Wiley, ISBN: 9780-471-49049-4, England

Pang, S.J; Zhang, T; Asami, K. \& Inoue, A. (2002). Synthesis of Fe-Cr-Mo-C-B-P Bulk Metallic Glasses with High Corrosion Resistance, Acta Materialia, 50, pp. 489-497

Rickerby, D.S. \& Matthews, A. (1991). Advanced Surface Coatings: A Handbook of Surface Engineering, Chapman and Hall, New York, 1991

Sauthoff, G. (1995). Intermetallics, VCH, Germany

Sampath, S; Gudrnundsson, B; Tiwari, R. \& Herman, H. (1990). Plasma Spray Consolidation of Ni-Al intermetallics, Thermal Spray Research and Applications,Proceeding of third National Thermal Spray Conference, pp. 357-361, Long Beach, ASM International, May 1990

Sampath, S; Jiang, X.Y. \& Matejicek, J. (2004). Role of Thermal Spray Processing Method on the Microstructure, Residual Stress and Properties of Coatings: an Integrated Study for Ni-5wt.\%Al Bond Coats, Materials Science and Engineering A, 236, pp. 216-232

Schmalzried, H. (1995). Chemical Kinetics of Solids, Wiley-VCH, Weinheim

Schuh, C.A; Hufnagel, T.C. \& Ramamurty, U. (2007). Mechanical Behavior of Amorphous Alloys, Acta Materialia, 55, 12, pp. 4067-4109

Shin, D.I; Gitzhofer, F. \& Moreau, C. (2007). Properties of Induction Plasma Sprayed Iron Based Nanostructured Alloy Coatings for Metal Based Thermal Barrier Coatings, Journal of Thermal Spray Technology, 16, 1, pp. 118-127 
Stein, A.; Keller, S.W. \& Mallouk, T.E. (1993). Turning Down the Heat: Design and Mechanism in Solid-State Synthesis. Science, 259, pp. 1558-1564

Stoloff, N.S; Liu, C.T. \& Deevi, S.C. (2000). Emerging Applications of Intermetallics, Intermetallics, 8, pp. 1313-1320

Totemeier, T.C. (2005). Effect of High-Velocity Oxygen-Fuel Thermal Spraying on the Physical and Mechanical Properties of Type 316 Stainless Steel, Journal of Thermal Spray Technology, 14, 3, pp 369-372

Steenkiste, T.H; Smith, J.R. \& Teets, R.E. (2002). Aluminium Coatings via Kinetic Spray with Relatively Large Powder Particle, Surface and Coating Technology, 154, pp. 237-252

Schwarz, R.B. \& Johnson, W.L. (1983). Formation of an Amorphous Alloy by Solid-State Reaction of the Pure Polycrystalline Metals, Physical Review Letter, 51, pp. 415-422

Sunol, J.J; Clavaguera, N. \& Cavaguera-Mora, M.T. (2001). Comparison of Fe-Ni-P-Si Alloys Prepared by Ball Milling, Journal of Non-Crystalline Solids, 287, pp. 114-119

Suryanarayana, C. (2001). Mechanical Alloying and Milling, Progress in Materials Science, 46, PP. 1-184

Suryanarayana, C. (2004). Mechanical Alloying and Milling, Marcel Dekker, 0-8247-4103-X, New York, USA

Wu, Y; Lin, P; Xie, G; Hu, J. \& Cao, M. (2006). Formation of Amorphous and Nanocrystalline Phases in High Velocity Oxy-Fuel Thermally Sprayed a Fe-Cr-Si-B-Mn Alloy, Materials Science and Engineering A, 430, pp. 34-39

Zhang, Q; Li, C.J; Wang, X.R; Ren, Z.L; Li, C.X. \& Yang, G.J. (2008). Formation of NiAl Intermetallic Compound by Cold Spraying of Ball-Milled Ni/Al Alloy Powder Through Post Annealing Treatment, Journal of Thermal Spray Technology, 17, 5-6, pp. 715-720

Zhang, D.L; Liang, J. \& Wu, J. (2004). Processing Ti 3 Al-SiC Nanocomposites High Energy Mechanical Milling, Materials Science and Engineering A, 375-377, pp 911-916

Zhang, D.L. (2004). Processing of Advanced Materials Using High-Energy Mechanical Milling, Progress in Materials Science 49, pp. 537-560 


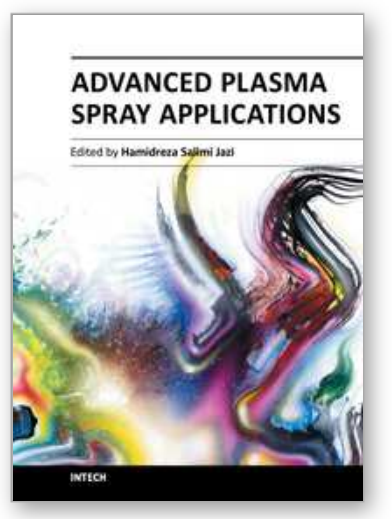

\author{
Advanced Plasma Spray Applications \\ Edited by Dr. Hamid Jazi
}

ISBN 978-953-51-0349-3

Hard cover, 250 pages

Publisher InTech

Published online 21, March, 2012

Published in print edition March, 2012

Recently, plasma spray has been received a large number of attentions for various type of applications due to the nature of the plasma plume and deposition structure. The plasma gas generated by the arc, consists of free electrons, ionized atoms, some neutral atoms, and undissociated diatomic molecules. The temperature of the core of the plasma jet may exceed up to $30,000 \mathrm{~K}$. Gas velocity in the plasma spray torch can be varied from subsonic to supersonic using converging-diverging nozzles. Heat transfer in the plasma jet is primarily the result of the recombination of the ions and re-association of atoms in diatomic gases on the powder surfaces and absorption of radiation. Taking advantages of the plasma plume atmosphere, plasma spray can be used for surface modification and treatment, especially for activation of polymer surfaces. I addition, plasma spray can be used to deposit nanostructures as well as advanced coating structures for new applications in wear and corrosion resistance. Some state-of-the-art studies of advanced applications of plasma spraying such as nanostructure coatings, surface modifications, biomaterial deposition, and anti wear and corrosion coatings are presented in this book.

\title{
How to reference
}

In order to correctly reference this scholarly work, feel free to copy and paste the following:

Behrooz Movahedi (2012). A Solid State Approach to Synthesis Advanced Nanomaterials for Thermal Spray Applications, Advanced Plasma Spray Applications, Dr. Hamid Jazi (Ed.), ISBN: 978-953-51-0349-3, InTech, Available from: http://www.intechopen.com/books/advanced-plasma-spray-applications/a-solid-state-approachto-synthesis-advanced-nanomaterials-for-thermal-spray-applications-

\section{INTECH}

open science | open minds

\section{InTech Europe}

University Campus STeP Ri

Slavka Krautzeka 83/A

51000 Rijeka, Croatia

Phone: +385 (51) 770447

Fax: +385 (51) 686166

www.intechopen.com

\section{InTech China}

Unit 405, Office Block, Hotel Equatorial Shanghai

No.65, Yan An Road (West), Shanghai, 200040, China 中国上海市延安西路65号上海国际贵都大饭店办公楼405单元

Phone: +86-21-62489820

Fax: +86-21-62489821 
(C) 2012 The Author(s). Licensee IntechOpen. This is an open access article distributed under the terms of the Creative Commons Attribution 3.0 License, which permits unrestricted use, distribution, and reproduction in any medium, provided the original work is properly cited. 